DOI: 10.1002/ ((please add manuscript number))

Article type: (Full Paper)

\title{
Bioorthogonal Photo-Catalytic Activation of an Anti-Cancer Prodrug by Riboflavin
}

Xin Yang ${ }^{+}$, Limin Ma ${ }^{+}$, Hongwei Shao ${ }^{+}$Xia Ling, Mengyu Yao, Guowen Luo, Gloria Mazzone, * Meng Gao, * and Ben Zhong Tang*

X. Yang, X. Ling, Prof. M. Gao

National Engineering Research Center for Tissue Restoration and Reconstruction, Key Laboratory of Biomedical Engineering of Guangdong Province, Key Laboratory of Biomedical Materials and Engineering of the Ministry of Education, Innovation Center for Tissue Restoration and Reconstruction, South China University of Technology, Guangzhou 510006, China

E-mail:msmgao@scut.edu.cn

H. Shao, M. Yao, G. Luo, Prof. L. Ma

Department of Orthopedics, Guangdong Provincial People's Hospital, Guangdong Academy

of Medical Sciences, Guangzhou, Guangdong, 510080, China

E-mail: malimin7@126.com

Prof. Gloria Mazzone

Department of Chemistry and Chemical Technologies, Università della Calabria, 87036 Arcavacata di Rende, CS, Italy.

E-mail: gloria.mazzone@unical.it

Prof. B. Z. Tang

AIE institute, State Key Laboratory of Luminescent Materials and Devices, Center for Aggregation-Induced Emission, Guangdong Provincial Key Laboratory of Luminescence from Molecular Aggregates, Guangzhou International Campus, South China University of Technology, Guangzhou 510640; Shenzhen Institute of Aggregate Science and Technology, School of Science and Engineering, The Chinese University of Hong Kong, Shenzhen 518172, China

E-mail: tangbenz@cuhk.edu.cn

$\left.{ }^{+}\right]$These authors contributed equally to this work.

Keyword: biorthogonal photocatalysis, prodrug, cancer, riboflavin, fluorescence 


\section{Abstract}

Chemotherapies for cancer treatment usually suffer from poor targeting ability and serious side-effects. To improve the treatment efficiency and reduce side effects, photoactivatable chemotherapy has been recently proposed for precise cancer treatment with high spatiotemporal resolution. However, most photoactivatable prodrugs require decoration by stoichiometric photo-cleavable groups, which are only responsive to ultraviolet irradiation and suffer from low reaction efficiency. To tackle these challenges, we herein propose a bioorthogonal photo-catalytic activation strategy with riboflavin as the catalyst for in situ transformation of prodrug dihydrochelerythrine (DHCHE) prodrug into anti-cancer drug chelerythrine (CHE), which can efficiently kill cancer cells and inhibit in vivo tumor growth under light irradiation. Meanwhile, the photo-catalytic transformation from DHCHE into CHE can be in situ monitored by green-to-red fluorescence conversion, which can be used for precise control of the therapeutic dose. We believe this imaging-guided bioorthogonal photocatalytic strategy is promising for cancer treatment in clinical applications.

\section{Introduction}

Chemotherapy usually suffers from serious side-effects due to the off-target toxicity. ${ }^{[1]}$ Therefore, it's highly desirable for precise activation of chemotherapy at tumor sites to improve treatment efficiency and reduce side effects. To achieve precise cancer treatment, various external stimuli-responsive strategies have been proposed for in situ activation of prodrugs, such as $\mathrm{pH}$, enzymes and photoirradiation. ${ }^{[2]}$ Among these methods, the photoactivation strategy is featured with the significant advantage of high spatiotemporal resolution and is especially suitable for treatment of shallow-seated tumors. ${ }^{[3]}$ However, conventional photoactivatable chemotherapy usually requires decoration of chemotherapeutics with stoichiometric photo-responsive groups, ${ }^{[4]}$ which not only require tedious synthetic procedures for preparation, but also suffer from low photoactivation efficiency and easy generation of toxic byproducts. Moreover, most of current photo- 
responsive groups are only responsive to cytotoxic ultraviolet (UV) irradiation with low absorption coefficients, which seriously restrict their in vivo applications. ${ }^{[4 c]}$

Recently, photocatalytic activation of chemotherapeutics has been proposed to greatly improve the chemotherapy efficiency. ${ }^{[5]}$ Compared with metal catalysts, biogenic organic photocatalysts are more attractive for in vivo applications with excellent biocompatibility. ${ }^{[6]}$ For example, riboflavin (Rf) as the precursor of flavin cofactors has been used for the activation of $\mathrm{Pt}^{\mathrm{IV}}$ and $\mathrm{Ru}^{\mathrm{IV}}$ prodrugs via photo-reduction reactions. ${ }^{[7-8]}$ Herein, based on our previous study of photoactivatable imaging and cancer therapies, ${ }^{[9]}$ we proposed a biorthogonal photocatalytic strategy with riboflavin as the photocatalyst for in situ activation of the non-toxic prodrug dihydrochelerythrine (DHCHE) into anticancer drug chelerythrine (CHE) under white light or blue light irradiation. The photocatalytic mechanism was fully explored by means of density functional theory (DFT) calculations. With A375 cancer cells and melanoma tumor bearing mice as a model, the combination of "DHCHE + Rf" under light irradiation showed a high efficiency for killing of cancer cells and inhibition of in vivo tumor growth. Meanwhile, the photocatalytic activation from DHCHE into CHE can be in situ monitored by green-to-red fluorescence conversion, which can be used for precise control of the therapeutic dose.

\section{Results and Discussion}

\subsection{Photocatalytic transformation from DHCHE into CHE}

With DHCHE as the prodrug, we first screened a series of photocatalysts to promote its transformation into anticancer drug $\mathrm{CHE}$, including $\left[\mathrm{Ru}(\mathrm{bpy})_{3}\right]^{2+}$, tetraphenylporphyrin, Al(III) phthalocyanine chloride tetrasulfonic acid, hemin, methylene blue, rose bengal, 9mesityl-10-methylacridinium perchlorate and riboflavin (Figure S1, Supporting Information). Among these photocatalysts, only riboflavin can efficiently promote the transformation from DHCHE into CHE, which was verified by UV-Vis absorption and HPLC spectra measurement (Figure 1B-D). As shown in Figure 1C, for "DHCHE $(100 \mu \mathrm{M})+\operatorname{Rf}(50 \mu \mathrm{M})$ " 
in aqueous solution under white light irradiation $\left(34 \mathrm{~mW} \mathrm{~cm}^{-2}\right)$, the absorption intensities at $266 \mathrm{~nm}$ and $318 \mathrm{~nm}$ gradually increased, which can be ascribed to the generation of CHE. The conversion efficiency from DHCHE to CHE also increased with the increasing $\mathrm{Rf}$ concentration, which was verified by the absorbance spectra measurement (Figure S2, Supporting Information). The photocatalytic transformation from DHCHE into CHE was also verified by HPLC spectra measurement. For "DHCHE $\left(0.5 \mathrm{mg} \mathrm{mL}^{-1}\right)+\mathrm{Rf}\left(0.05 \mathrm{mg} \mathrm{mL}^{-1}\right)$ " under blue light irradiation $\left(500 \mathrm{~nm}, 50 \mathrm{~mW} \mathrm{~cm}^{-2}\right)$ for $30 \mathrm{~min}$, the integration value of DHCHE peak decreased from $95.7 \%$ to $5.3 \%$, while the integration value of CHE peak increased from $0.4 \%$ to $70.1 \%$ (Figure 1E, Figure S3, Supporting Information). Interestingly, a faster transformation from DHCHE into CHE was observed in weakly acidic solution $(\mathrm{pH}=$ 6) than in neutral or weakly basic solution ( $\mathrm{pH}=7$ or 8) (Figure $\mathbf{S 4}$, Supporting Information), which suggests the combination of "DHCHE + Rf" under light irradiation is especially suitable for photoactivatable treatment of tumor with a weakly acidic environment $(\mathrm{pH} \sim 6) .{ }^{[10]}$

\subsection{Photocatalytic mechanism}

Computational approaches were exploited to shed light on the photocatalytic mechanism of DHCHE conversion to $\mathrm{CHE}$ by $\mathrm{Rf}$. A possible photocatalytic reaction mechanism was proposed in Scheme 2. Upon light irradiation, Rf singlet exited state can undergo intersystem crossing (ISC) to triplet state ${ }^{3} \mathrm{Rf}$ and then react with DHCHE via an electron transfer process to afford $\mathrm{Rf}^{\cdot-}$ and $\mathrm{DHCHE}^{\cdot+}$, which then undergo hydrogen abstraction reaction to yield $\mathrm{HRf}^{-}$ and CHE. The HRf ${ }^{-}$intermediate can be oxidized by oxygen to regenerate Rf (Scheme 2 , Figure S5, Supporting Information) ${ }^{[11]}$ In order to verify that the excited triplet state ${ }^{3} \mathrm{Rf}^{*}$ as an electron acceptor is critical to promote the transformation from DHCHE into CHE, Trolox was used as an electron donor to quench ${ }^{3} \mathrm{Rf}^{*}$ and the photocatalytic transformation was

efficiently inhibited (Figure S6, Supporting Information). ${ }^{[12]}$ Moreover, the low oxidation 
potential of DHCHE $\left(E_{\mathrm{ox}}=0.25 \mathrm{~V}\right)$ suggests that it can be easily oxidized by ${ }^{3} \mathrm{Rf}^{*}\left(E_{\mathrm{ox}}=1.77\right.$ V) via photoinduced electron transfer process (Figure S7, Supporting Information). ${ }^{[13]}$

The computational exploration of the photophysical Rf properties confirms that it can be excited under blue light irradiation causing a $\pi \rightarrow \pi^{*}$ transition (as evidenced by HOMO and LUMO plots in Figure 2A) and then an intersystem spin crossing from the bright state to the triplet manifold can occur. Indeed, the spin-orbit coupling values, accounting for ISC kinetics, suggest the viability of a preferential ISC channel $S_{1} \rightarrow T_{1}\left(S O C=14.2 \mathrm{~cm}^{-1}\right)$, here labelled as ${ }^{3} \mathrm{Rf}^{*}$ (Figure $\left.2 \mathrm{~A}\right)$.

To further ascertain that an electron transfer from DHCHE to ${ }^{3} \mathrm{Rf}^{*}$ could occur and to evaluate the energy gain of this process, the computation of radical anion and cation of $\mathrm{Rf}$ and DHCHE energies, respectively, were taken into consideration. With respect to the reactants' energy sum $\left({ }^{3} \mathrm{Rf}^{*}+\mathrm{DHCHE}\right)$, the electron shift for $\mathrm{Rf}^{{ }^{-}}$and $\mathrm{DHCHE}^{\cdot+}$ formation entails an energy gain of $12.9 \mathrm{kcal} \mathrm{mol}^{-1}$. Therefore, once $\mathrm{Rf}$ is excited and the ${ }^{3} \mathrm{Rf}^{*}$ triplet state results populated, an electron is transferred from DHCHE to ${ }^{3} \mathrm{Rf}^{*}$ to afford $\mathrm{Rf}^{{ }^{-}}$and $\mathrm{DHCHE}{ }^{*+}$. From here, for the sake of comparison and to prove that the subsequent hydrogen abstraction from DHCHE by $\mathrm{Rf}$ is facilitated when the $\mathrm{Rf}$ in its triplet state is involved in the reaction mechanism, such step was explored even along the ground state singlet energy surface (black line in Figure 2B). In both spin multiplicities, the initial (Rf $\cdots$ DHCHE) is characterized by a $\pi-\pi$ stacking interaction (Figure S8A, Supporting Information) and is stabilized of 25.5 and $10.3 \mathrm{kcal} \mathrm{mol}^{-1}$ along the triplet and singlet energy surfaces, respectively with respect to the corresponding reference energies of separated reactants.

The analysis of the spin density of $\mathrm{Rf}^{--}$.... $\mathrm{DHCHE}^{\cdot+}$ confirms the localization of the unpaired electrons on the key $\mathrm{N}$ atoms of $\mathrm{Rf}$ and DHCHE (Figure S8B, Supporting Information), as sketched in Scheme 2, accessible only along the triplet state energy surface. The hydrogen abstraction occurs through the transition state labelled $\mathrm{TS}_{\mathrm{H}}$ in which the hydrogen atom is almost transferred from the $\mathrm{C}$ atom of DHCHE to the $\mathrm{N}$ atom of Rf (Figure 
S8C, Supporting Information). The energy barrier to be overcome to yield $\mathrm{HRf}^{-}$and CHE is significantly lower along the triplet surface than the singlet one (6.6 vs $\left.21 \mathrm{kcal} \mathrm{mol}^{-1}\right)$. Along the triplet free energy profile such a transfer is realized by a hydrogen atom $(\mathrm{H} \cdot)$ migration starting from the $\mathrm{Rf}^{*}$.... $\mathrm{DHCHE}^{*+}$ adduct in which the two unpaired electrons are localized separately on the two reactants, whereas along the singlet surface a hydride migration should occur. Along the kinetically favoured pathway (red line in Figure 2B) the whole reaction results only slightly endergonic. Therefore, it is reasonable to hypothesize that the reaction should be favoured if Rf is first excited and then reacts with DHCHE to afford the anticancer drug CHE.

The free energy surface describing a plausible restoring of Rf by molecular oxygen naturally present in the environment is reported in Figure 2C. At physiological pH, it can be hypothesized that the $\mathrm{HRf}^{-}$species, formed according to the photocatalytic mechanism described above, is converted into its di-protonated form $\mathrm{H}_{2} \mathrm{Rf}$ depicted in Scheme 2. Thus, the reaction between $\mathrm{H}_{2} \mathrm{Rf}$ and $\mathrm{O}_{2}$ leading to the formation of $\mathrm{Rf}$ and $\mathrm{H}_{2} \mathrm{O}_{2}$ was explored and the optimized structures of the intercepted stationary points are reported in Figure S9. As one of the reactants, molecular oxygen, is in its ground triplet state the reaction mechanism surely starts in triplet state. Along such free energy profile, the reaction passes through two transition state that require substantially different amounts of energy to be overcome. The first $\mathrm{H}$ abstraction occurs overcoming an energy barrier of only $5.7 \mathrm{kcal} \mathrm{mol}^{-1}$ and the formed product, that is the adduct between HRf and $\mathrm{OOH}(\mathrm{HRf} \cdots \mathrm{OOH})$, lies $3.1 \mathrm{kcal} \mathrm{mol}^{-1}$ above the reference. The subsequent $\mathrm{H}$ abstraction requires the overcoming of an energy barrier five times higher than the first one. However, the final product, that is the adduct between the restored $\mathrm{Rf}$ and the $\mathrm{H}_{2} \mathrm{O}_{2}$, results much more stable along the singlet free energy surface (green line in Figure 2C). As a consequence, a spin crossing from the triplet to the singlet spin surface has to occur. In addition, all the numerous attempts carried out to locate a transition state for the second hydrogen transfer along such surface failed, meaning that when 
the $\mathrm{OOH}$ moiety comes close to the $\mathrm{NH}$ site it is rapidly converted into $\mathrm{H}_{2} \mathrm{O}_{2}$ and the Rf is thus restored.

\subsection{Cancer Cell Imaging and Killing}

We then investigated the cancer cell imaging and killing ability of "Rf + DHCHE" with melanoma A375 cells as a model. For cells treated with "DHCHE $(50 \mu \mathrm{M})+\mathrm{Rf}(10$ $\mu \mathrm{M})$ " under white light irradiation $\left(34 \mathrm{~mW} \mathrm{~cm}^{-2}\right)$ for only $1.0 \mathrm{~min}$, an obviously turn-on red fluorescence in nucleus and a decreased green fluorescence in cytoplasm was observed under confocal laser scanning microscope (CLSM) (Figure 3A-B). In contrast, only a green fluorescence was observed in cytoplasm for treatment with only DHCHE $(50 \mu \mathrm{M})$ under light irradiation. These results suggest that $\mathrm{Rf}$ as a photocatalyst can efficiently promote the intramolecular transformation of green-emissive DHCHE in cytoplasm into red-emissive CHE with nucleus targeting ability.

The cancer cell killing ability of "Rf + DHCHE" was then investigated via MTT assay. The cancer cell viability decreased to almost zero by treatment with "DHCHE $(20 \mu \mathrm{M})+\mathrm{Rf}$ $(5 \mu \mathrm{M})$ " under white light irradiation $\left(34 \mathrm{~mW} \mathrm{~cm}^{-2}\right)$ for $10 \mathrm{~min}$ (Figure 3E-F). In contrast, a high cell viability (>60\%) was observed for treatment with only DHCHE (20 $\mu \mathrm{M})$ or Rf (20 $\mu \mathrm{M}$ ) (Figure 3C-D). These results suggest that the fast transformation from DHCHE into CHE catalyzed by Rf can efficiently kill cancer cells (Figure S10, Supporting Information).

The Annexin V-FITC/propidium iodide (PI) assay was then conducted for monitoring of cell apoptosis induced by "DHCHE + Rf" under light irradiation $(+\mathrm{L})$. The A375 cells were first treated with "DHCHE$(50 \mu \mathrm{M})+\mathrm{Rf}(10 \mu \mathrm{M})$ " for 30 min and then irradiated by white light $\left(34 \mathrm{~mW} \mathrm{~cm}^{-2}\right)$ for $10 \mathrm{~min}$, the cytoplasm and nucleus were respectively stained with Annexin V-FITC/PI, which suggests "DHCHE + Rf (+ L)" can efficiently induce cancer cell apoptosis (Figure 4A-B). ${ }^{[14]}$ The flow cytometry analysis was also conducted and a much higher apoptotic ratio (61.40\%) was observed for "DHCHE $+\mathrm{Rf}(+\mathrm{L})$ " group than the other groups, such as "DHCHE (+ L)" (12.95\%) and "Rf (+ L)" (12.86\%) (Figure S11, Supporting 
Information). The apoptosis mechanism was then investigated via quantitative reverse transcription PCR (qRT-PCR) analysis. A significantly higher expression of pro-apoptotic genes (Bax, P53 and Caspase-3) and a lower expression of anti-apoptotic gene (Bcl2) were observed for the "DHCHE + Rf (+ L)" group than the other groups (Figure 4C-D, Table S1, Supporting Information). ${ }^{[15]}$ The apoptosis-inducing ability of "DHCHE $+\mathrm{Rf}(+\mathrm{L})$ " can be ascribed to the efficient transformation into cytotoxic CHE associating with generation of reactive oxygen species (ROS) (Figure S12-S13, Supporting Information). ${ }^{[16]}$

\subsection{Inhibition of Tumor Growth}

The in vivo tumor inhibition experiment was performed with melanoma A375-bearing nude mice as a model, which were randomly divided into seven groups: Control, DHCHE, DHCHE (+ L), Rf, Rf (+ L), “DHCHE + Rf”, and “DHCHE + Rf (+ L)”. Different groups were treated with the corresponding agents every 2 days by intertumoral injection. For light irradiation $(+\mathrm{L})$ groups, the mice were irradiated under blue light irradiation $(500 \mathrm{~nm}, 50 \mathrm{~mW}$ $\mathrm{cm}^{-2}$ ) for $30 \mathrm{~min}$ after intertumoral injection of therapeutic agents. As shown in Figure 5B, the body weight of mice did not show obvious decrease for all groups after treatment for 14 days, whereas the tumor volume and weight of "DHCHE $+\mathrm{Rf}(+\mathrm{L})$ " group was much lower than the other groups (Figure 5C-D). The tumors were then dissected and analyzed by hematoxylin and eosin (H\&E) and immunohistochemical staining (Figure 5E). For the "DHCHE + Rf (+ L)" group, an obviously increased vacuole and condensed nuclei were observed. It also showed the highest expression of pro-apoptotic Caspace-3 and lowest expression of anti-apoptotic Ki-67 among the treatment groups (Figure 5F). These results suggest that the tumor growth can be efficiently inhibited by "DHCHE + Rf (+ L)".

\subsection{In Vivo Biosafety Evaluation}

In order to evaluate the biosafety, major organs were collected and analyzed by H\&E staining after treatment for 14 days. Compared with healthy nude mice (blank group) and control group treated with physiological saline, the "DHCHE + Rf $(+\mathrm{L})$ " group did not show obvious 
inflammation lesions or impairment (Figure 6A). Meanwhile, the expression level of blood indicators were comparable for different treatment groups, including blood urea nitrogen (BUN), alanine aminotransferase (ALT), aspartate aminotransferase (AST) and total protein (TP). These results suggest that "DHCHE $+\mathrm{Rf}(+\mathrm{L})$ " has an excellent biocompatibility (Figure 6B-E).

\section{Conclusion}

In conclusion, we proposed a photocatalytic activation strategy for in situ and fast transformation of DHCHE into anticancer-active CHE with $\mathrm{Rf}$ as the bioorthogonal photocatalyst, which showed a high efficiency for inducing cancer cell apoptosis in vitro and inhibition of tumor growth in vivo. Meanwhile, the photocatalytic activation process can be in situ monitored by fluorescence imaging, which can be used for precise control of the therapeutic dose. We believe this biorthogonal photocatalytic activation strategy for chemotherapy is promising for precise cancer treatment.

\section{Experimental Section}

Cell Imaging: The A375 cells in culture media were first treated with "DHCHE $(50 \mu \mathrm{M})+\mathrm{Rf}$ $(10 \mu \mathrm{M})$ " or DHCHE $(50 \mu \mathrm{M})$ for $30 \mathrm{~min}$, and then the cells were irradiated under white light irradiation $\left(34 \mathrm{~mW} \mathrm{~cm}^{-2}\right)$ for different time. The CLSM images were then taken under confocal microscope. For DHCHE (green channel), $\lambda_{\mathrm{ex}}=405 \mathrm{~nm}, \lambda_{\mathrm{em}}=420-520 \mathrm{~nm}$. For CHE (red channel), $\lambda_{\mathrm{ex}}=488 \mathrm{~nm}, \lambda_{\mathrm{em}}=580-700 \mathrm{~nm}$. Scale bar $=20 \mu \mathrm{m}$.

Apoptosis In Situ Monitored by CLSM: The A375 cells in culture media were first treated with “DHCHE $(50 \mu \mathrm{M})+\mathrm{Rf}(10 \mu \mathrm{M})$ ” for 30 min and further treated with Annexin V-FITC/PI for $10 \mathrm{~min}$, then the cells were irradiated under white light irradiation $\left(34 \mathrm{~mW} \mathrm{~cm}^{-2}\right)$ for different time. The CLSM images were then taken under confocal microscope. For DHCHE, $\lambda_{\mathrm{ex}}=405$ $\mathrm{nm}, \lambda_{\mathrm{em}}=420-520 \mathrm{~nm}$. For CHE, $\lambda_{\mathrm{ex}}=488 \mathrm{~nm}, \lambda_{\mathrm{em}}=580-700 \mathrm{~nm}$. For Annexin V-FITC, $\lambda_{\mathrm{ex}}$ $=488 \mathrm{~nm}, \lambda_{\mathrm{em}}=510-550 \mathrm{~nm}$. For PI, $\lambda_{\mathrm{ex}}=543 \mathrm{~nm}, \lambda_{\mathrm{em}}=560-625 \mathrm{~nm}$. Scale bar $=20 \mu \mathrm{m}$. 
Apoptosis Analyzed by Flow Cytometry: The A375 cells were seeded into six-well plates (2.5 $\times 10^{5}$ cells/well) for $24 \mathrm{~h}$. After incubation of cells with different therapeutic agents for 30 min, including "DHCHE $(20 \mu \mathrm{M})+\mathrm{Rf}(10 \mu \mathrm{M})$ ", DHCHE $(20 \mu \mathrm{M})$ and Rf $(10 \mu \mathrm{M})$, the cells were further irradiated under white light irradiation $\left(34 \mathrm{~mW} \mathrm{~cm}^{-2}\right)$ for $10 \mathrm{~min}$. After further incubation at $37^{\circ} \mathrm{C}$ for $24 \mathrm{~h}$, the cells were collected and treated with Annexin V-FITC/PI for $15 \mathrm{~min}$. The percentage of apoptotic ratio was then analyzed by flow cytometry.

In Vivo Tumor Therapy: All mice experiments were approved by Animal Center of South China University of Technology and were performed in compliance with the Regulation on the Administration of Laboratory Animals established by the State Council, the People's Republic of China. Briefly, A375 cells $\left(2 \times 10^{6}\right)$ were subcutaneous injected into right back positions to establish the tumor model of Balb/c nude mice. When the tumor volume reached approximately $200 \mathrm{~mm}^{3}$, the mice were randomly divided into seven groups: control group (PBS), DHCHE (2.0 mg kg-1), DHCHE (+ L) group (2.0 $\left.\mathrm{mg} \mathrm{kg}^{-1}\right)$, Rf group $\left(1.0 \mathrm{mg} \mathrm{kg}^{-1}\right)$, Rf (+ L) group (1.0 mg kg-1), "DHCHE + Rf " group (2.0 $\mathrm{mg} \mathrm{kg}^{-1}$ DHCHE and $1.0 \mathrm{mg} \mathrm{kg}^{-1}$ Rf), "DHCHE + Rf (+ L)" group (2.0 mg kg-1 DHCHE and $\left.1.0 \mathrm{mg} \mathrm{kg}^{-1} \mathrm{Rf}\right)(\mathrm{n}=5$ for each group). The mice were treated with corresponding therapeutic agents every 2 days by intratumoral injection and the tumor region was irradiated with $500 \mathrm{~nm}$ light $\left(50 \mathrm{~mW} \mathrm{~cm}{ }^{-2}, 30\right.$ min). During the treatment period, the tumor volume of all mice was measured every 2 days using a vernier caliper (tumor volume $\mathrm{V}=\mathrm{L} * \mathrm{~W}^{2} / 2, \mathrm{~L}$ is tumor length and $\mathrm{W}$ is tumor wide). After treatment for 14 days, all the mice were sacrificed and the major organs and tumors collected from the bodies were analyzed by H\&E and immunohistochemical staining.

\section{Supporting Information}

Supporting Information is available from the Wiley Online Library or from the author.

\section{Acknowledgements}

This work was financially supported by the National Science Foundation of China (21788102, 51620105009, 22175065, 21877040, U1801252); the National Key R\&D Program of China 
(2018YFC0311103); the Science and Technology Planning Project of Guangzhou (201804020060, 202007020002 and 201607020015); Natural Science Foundation of Guangdong Province (2020B1515020010, 2020A1515110746, 2020B0101030006 and 2020A1515010827); the High-level Hospital Construction Project (KJ012019100); the University of Calabria and Calabria Region (project POR Calabria-FSE/FESR 2014-2020) for financial support.

\section{Conflict of Interest}

The authors declare no conflict of interest.

\section{References}

[1] a) M. Gao, B. Z. Tang, Coord. Chem. Rev. 2020, 402, 213076; b) W. Liu, X. Luo, Y. Bao, Y. P. Liu, G. H. Ning, I. Abdelwahab, L. Li, C. T. Nai, Z. G. Hu, D. Zhao, B. Liu, S. Y. Quek, K. P. Loh, Nat. Chem. 2017, 9, 563-570; c) M. T. Manzari, Y. Shamay, H. Kiguchi, N. Rosen, M. Scaltriti, D. A. Heller, Nat. Rev. Mater. 2021, 6, 351-370.

[2] a) M. A. Rahim, N. Jan, S. Khan, H. Shah, A. Madni, A. Khan, A. Jabar, S. Khan, A. Elhissi, Z. Hussain, H. C. Aziz, M. Sohail, M. Khan, H. E. Thu, Cancers 2021, 13, 670; b) S. Municoy, M. I. Alvarez Echazu, P. E. Antezana, J. M. Galdoporpora, C. Olivetti, A. M. Mebert, M. L. Foglia, M. V. Tuttolomondo, G. S. Alvarez, J. G. Hardy, M. F. Desimone, Int. J. Mol. Sci. 2020, 21, 4724; c) Y. Zhang, C. Xu, X. Yang, K. Pu, Adv. Mater. 2020, 32, 2002661; d) M. Kang, Z. Zhang, N. Song, M. Li, P. Sun, X. Chen, D. Wang, B. Z. Tang, Aggregate 2020, 1, 80-106; e) J. Hu, W. Jiang, L. Yuan, C. Duan, Q. Yuan, Z. Long, X. Lou, F. Xia, Aggregate 2021, 2, 48-56.

[3] a) S. Bonnet, Dalton Trans. 2018, 47, 10330-10343; b) F. Zhang, Q. Wu, H. Liu, WIREs Nanomed Nanobiotechnol.. 2020, 12, e1643; c) A. Presa, G. Vazquez, L. A. Barrios, O. Roubeau, L. Korrodi-Gregorio, R. Perez-Tomas, P. Gamez, Inorg. Chem. 2018, 57, 4009-4022; d) C. Matera, A. M. J. Gomila, N. Camarero, M. Libergoli, C. Soler, P. Gorostiza, J. Am. Chem. Soc. 2018, 140, 15764-15773; e) F. Reessing, W. 
Szymanski, Curr. Med. Chem. 2017, 24, 4905-4950; f) J. A. Cuello-Garibo, M. S. Meijer, S. Bonnet, Chem. Commun. 2017, 53, 6768-6771; g) C. Mari, V. Pierroz, A. Leonidova, S. Ferrari, G. Gasser, Eur. J. Inorg. Chem. 2015, 3879-3891; h) Y. Chen, W. Lei, G. Jiang, Y. Hou, C. Li, B. Zhang, Q. Zhou, X. Wang, Dalton Trans. 2014, 43, $15375-15384$.

[4] a) Z. Wang, N. Wang, S.-C. Cheng, K. Xu, Z. Deng, S. Chen, Z. Xu, K. Xie, M.-K. Tse, P. Shi, H. Hirao, C.-C. Ko, G. Zhu, Chem 2019, 5, 3151-3165; b) V. H. S. van Rixel, V. Ramu, A. B. Auyeung, N. Beztsinna, D. Y. Leger, L. N. Lameijer, S. T. Hilt, S. E. Le Devedec, T. Yildiz, T. Betancourt, M. B. Gildner, T. W. Hudnall, V. Sol, B. Liagre, A. Kornienko, S. Bonnet, J. Am. Chem. Soc. 2019, 141, 18444-18454; c) P. Klan, T. Solomek, C. G. Bochet, A. Blanc, R. Givens, M. Rubina, V. Popik, A. Kostikov, J. Wirz, Chem. Rev. 2013, 113, 119-191.

[5] a) Z. Du, C. Liu, H. Song, P. Scott, Z. Liu, J. Ren, X. Qu, Chem 2020, 6, 2060-2072; b) F. Wang, Y. Zhang, Z. Du, J. Ren, X. Qu, Nat. Commun. 2018, 9, 1209; c) G. Y. Tonga, Y. Jeong, B. Duncan, T. Mizuhara, R. Mout, R. Das, S. T. Kim, Y.-C. Yeh, B. Yan, S. Hou, V. M. Rotello, Nat. Chem. 2015, 7, 597-603; d) T. Voelker, F. Dempwolff, P. L. Graumann, E. Meggers, Angew. Chem., Int. Ed. 2014, 53, 1053610540; e) J. G. Rebelein, T. R. Ward, Curr. Opin. Biotechnol. 2018, 53, 106-114; f) D. M. Patterson, L. A. Nazarova, J. A. Prescher, ACS Chem. Biol. 2014, 9, 592-605.

[6] a) M. Darguzyte, R. Holm, J. Baier, N. Drude, J. Schultze, K. Koynov, D. Schwiertz, S. M. Dadfar, T. Lammers, M. Barz, F. Kiessling, Bioconjugate Chem. 2020, 31, 2691-2696; b) M. Darguzyte, N. Drude, T. Lammers, F. Kiessling, Cancers 2020, 12, 295; c) Y. Tsvetkova, N. Beztsinna, M. Baues, D. Klein, A. Rix, S. K. Golombek, W. Al Rawashdeh, F. Gremse, M. Barz, K. Koynov, S. Banala, W. Lederle, T. Lammers, F. Kiessling, Nano Lett. 2017, 17, 4665-4674; d) S. Pal, C. Dalal, N. R. Jana, ACS 
Omega 2017, 2, 8948-8958; e) N. Beztsinna, Y. Tsvetkova, M. Bartneck, T. Lammers, F. Kiessling, I. Bestel, Bioconjugate Chem. 2016, 27, 2048-2061.

[7] a) L. Xu, X. Liang, S. Zhang, B. Wang, S. Zhong, M. Wang, X. Cui, Dyes Pigm. 2020, 182, 108642; b) B. König, S. Kümmel, E. Svobodová, R. Cibulka, Phys. Sci. Rev. 2018, 3, 20170168; c) G. de Gonzalo, M. W. Fraaije, ChemCatChem. 2013, 5, 403415; d) S. Bloom, C. Liu, D. K. Kolmel, J. X. Qiao, Y. Zhang, M. A. Poss, W. R. Ewing, D. W. C. MacMillan, Nat. Chem. 2018, 10, 205-211.

[8] a) S. Alonso-de Castro, A. L. Cortajarena, F. Lopez-Gallego, L. Salassa, Angew. Chem., Int. Ed. 2018, 57, 3143-3147. b) R. Zhang, X. Song, Y. Liu, P. Wang, Z. Wang, Z. Zheng, Y. Dai, B. Huang, J. Mater. Chem. A 2019, 7, 26934-26943.

[9] a) X. Ling, L. Huang, Y. Li, Q. Wan, Z. Wang, A. Qin, M. Gao, B. Z. Tang, Mater. Horiz. 2020, 7, 2696-2701; b) S. Li, X. Ling, Y. Lin, A. Qin, M. Gao, B. Z. Tang, Chem. Sci. 2018, 9, 5730-5735.

[10] a) D. S. Benoit, H. Koo, Nanomedicine. 2016, 11, 873-879; b) M. Upreti, A. Jyoti, P. Sethi, Transl. Cancer Res. 2013, 2, 309-319; c) S. Thakkar, D. Sharma, K. Kalia, R. K. Tekade, Acta Biomater. 2020, 101, 43-68; d) Y.-L. Su, T.-W. Yu, W.-H. Chiang, H.-C. Chiu, C.-H. Chang, C.-S. Chiang, S.-H. Hu, Adv. Funct. Mater. 2017, 27, 1700056.

[11] a) L. Crovetto, V. Martinez-Junza, S. E. Braslavsky, Photochem. Photobiol. 2006, 82, 281-290; b) C. Feldmeier, H. Bartling, K. Magerl, R. M. Gschwind, Angew. Chem., Int. Ed. 2015, 54, 1347-1351; c) T. Langenbacher, D. Immeln, B. Dick, T. Kottke, J. Am. Chem. Soc. 2009, 131, 14274-14280; d) U. Megerle, M. Wenninger, R. J. Kutta, R. Lechner, B. Konig, B. Dick, E. Riedle, Phys. Chem. Chem. Phys. 2011, 13, 8869-8880.

[12] a) D. R. Cardoso, K. Olsen, L. H. Skibsted, J. Agric. Food Chem. 2007, 55, 6285-6291; b) N. K. Hall, T. M. Chapman, H. J. Kim, D. B. Min, Food Chem. 2010, 118, 534-539; c) R. Shimizu, M. Yagi, A. Kikuchi, J. Photochem. Photobiol., B 2019, 191, 116-122. 
[13] a) S. Alonso-de Castro, E. Ruggiero, A. Ruiz-de-Angulo, E. Rezabal, J. C. MarequeRivas, X. Lopez, F. Lopez-Gallego, L. Salassa, Chem. Sci. 2017, 8, 4619-4625; b) D. R. Cardoso, S. H. Libardi, L. H. Skibsted, Food Funct. 2012, 3, 487-502; c) K. A. Korvinson, G. N. Hargenrader, J. Stevanovic, Y. Xie, J. Joseph, V. Maslak, C. M. Hadad, K. D. Glusac, J. Phys. Chem. A 2016, 120, 7294-7300.

[14] a) S. Kumar, P. Deepak, S. Kumar, P. K. Gautam, A. Acharya, J. Canc. Res. Ther. 2013, 9, 693-700; b) W. Lin, J. Huang, Z. Yuan, S. Feng, Y. Xie, W. Ma, Sci. Rep. 2017, 7, 2022.

[15] a) S. Kumar, M. S. Tomar, A. Acharya, Leuk. Lymphoma 2015, 56, 1846-1855; b) K. F. Wan, S. L. Chan, S. K. Sukumaran, M. C. Lee, V. C. Yu, J. Biol. Chem. 2008, 283, 8423-8433.

[16] a) Y. Zhang, P. Murugesan, K. Huang, H. Cai, Nat. Rev. Cardiol. 2020, 17, 170-194; b) G. R. Drummond, S. Selemidis, K. K. Griendling, C. G. Sobey, Nat. Rev. Drug Discovery 2011, 10, 453-471. 


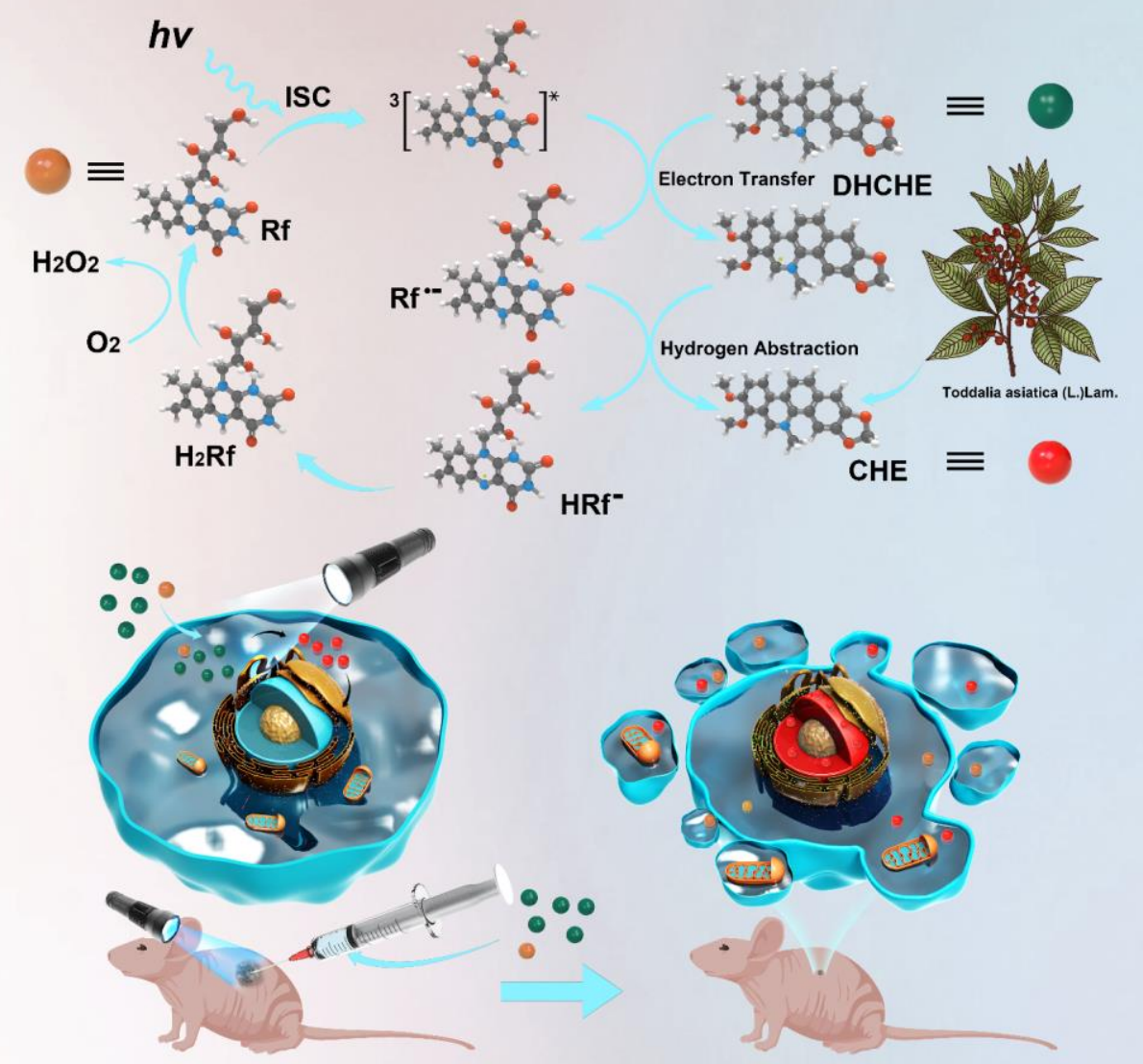

Scheme 1. Schematic illustration of photo-catalytic transformation of prodrug DHCHE into anti-cancer drug CHE with riboflavin as the bioorthogonal photocatalyst. 
A
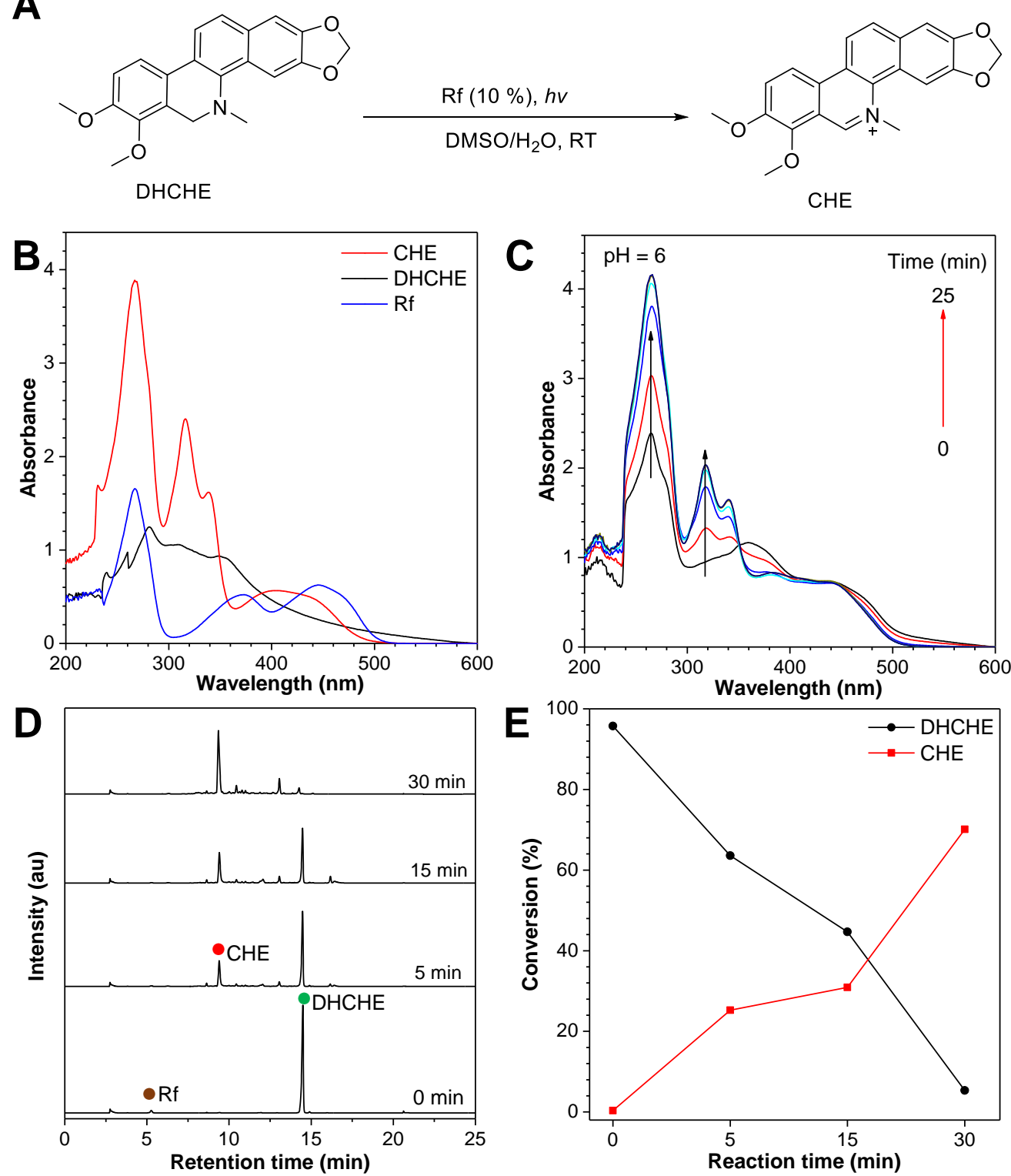

Figure 1. A) The photooxidative transformation from DHCHE into CHE promoted by riboflavin (Rf) in solution of DMSO/water ( $\mathrm{v}: \mathrm{v}=10: 90)$. B) Absorption spectra of DHCHE, $\mathrm{CHE}$ and $\mathrm{Rf}$ in Britton-Robinson buffer solution $(\mathrm{pH}=6$, DMSO/water ( $\mathrm{v}: \mathrm{v}=10: 90)$ ). $[\mathrm{DHCHE}]=100 \mu \mathrm{M},[\mathrm{CHE}]=100 \mu \mathrm{M},[\mathrm{Rf}]=50 \mu \mathrm{M}$. C) UV-Vis absorption spectra of "DHCHE + Rf" in Britton-Robinson buffer solution $(\mathrm{pH}=6$, DMSO/water ( $\mathrm{v}: \mathrm{v}=10: 90))$ under white light irradiation $\left(34 \mathrm{~mW} \mathrm{~cm}^{-2}\right)$. [DHCHE] $=100 \mu \mathrm{M},[\mathrm{Rf}]=50 \mu \mathrm{M}$; D E) Timedependent HPLC spectra and conversion ratio of DHCHE in the presence of Rf under blue light irradiation $\left(500 \mathrm{~nm}, 50 \mathrm{~mW} \mathrm{~cm}^{-2}\right)\left([\mathrm{DHCHE}]=0.5 \mathrm{mg} \mathrm{mL}^{-1},[\mathrm{Rf}]=0.05 \mathrm{mg} \mathrm{mL}^{-1}\right)$. $\mathrm{CHE}, \bullet \mathrm{DHCHE}$ and $\bullet \mathrm{Rf}$. 


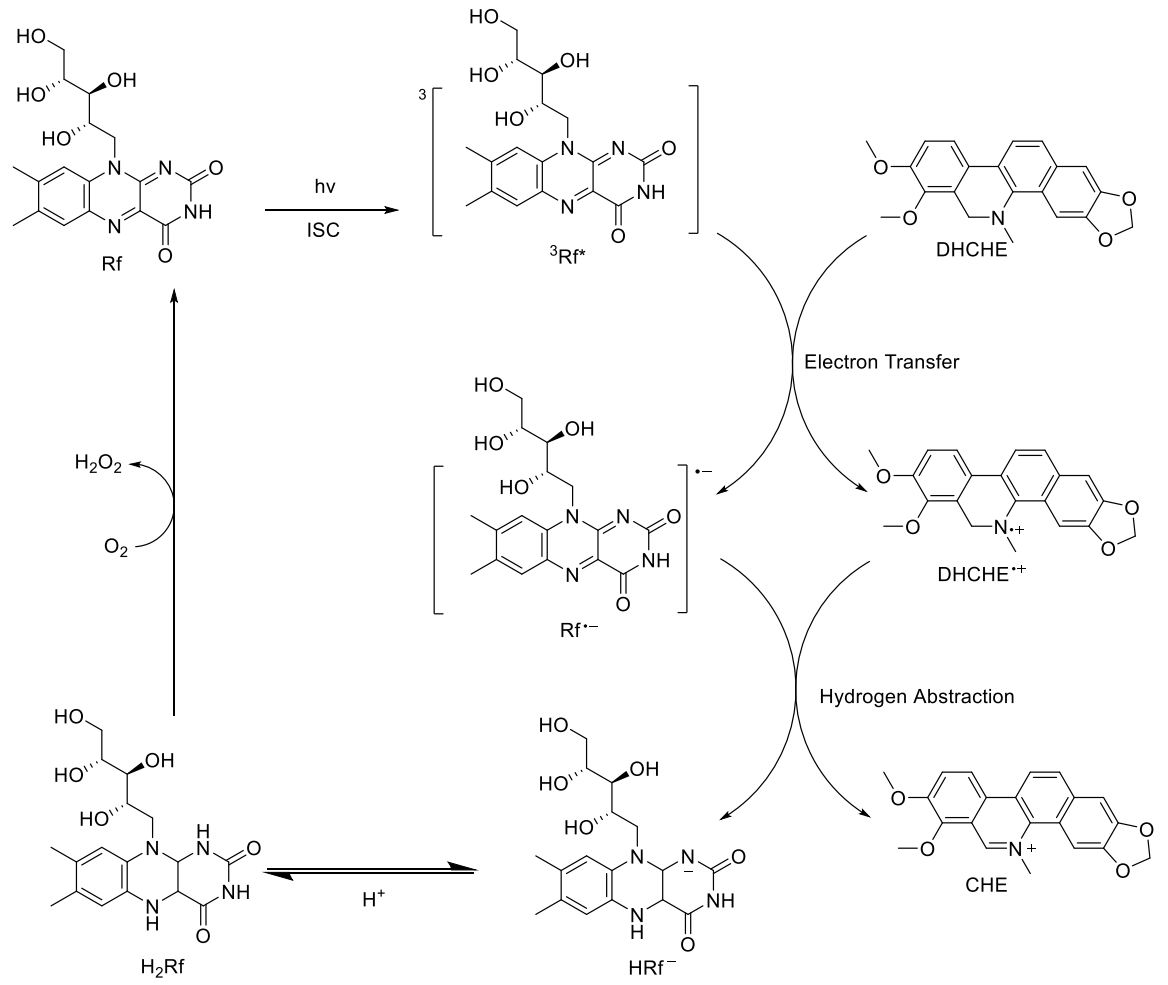

Scheme 2. The proposed reaction mechanism for catalyzed transformation from DHCHE into CHE with riboflavin as the photocatalyst. 


\section{A}

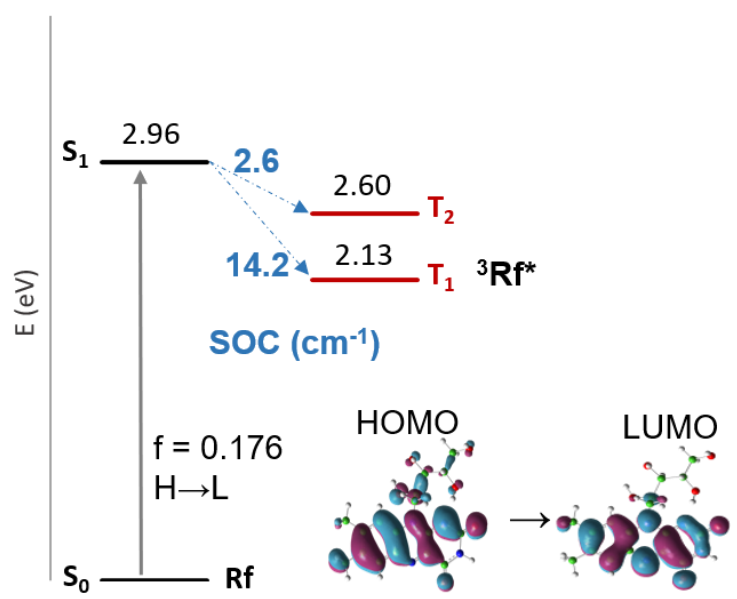

B
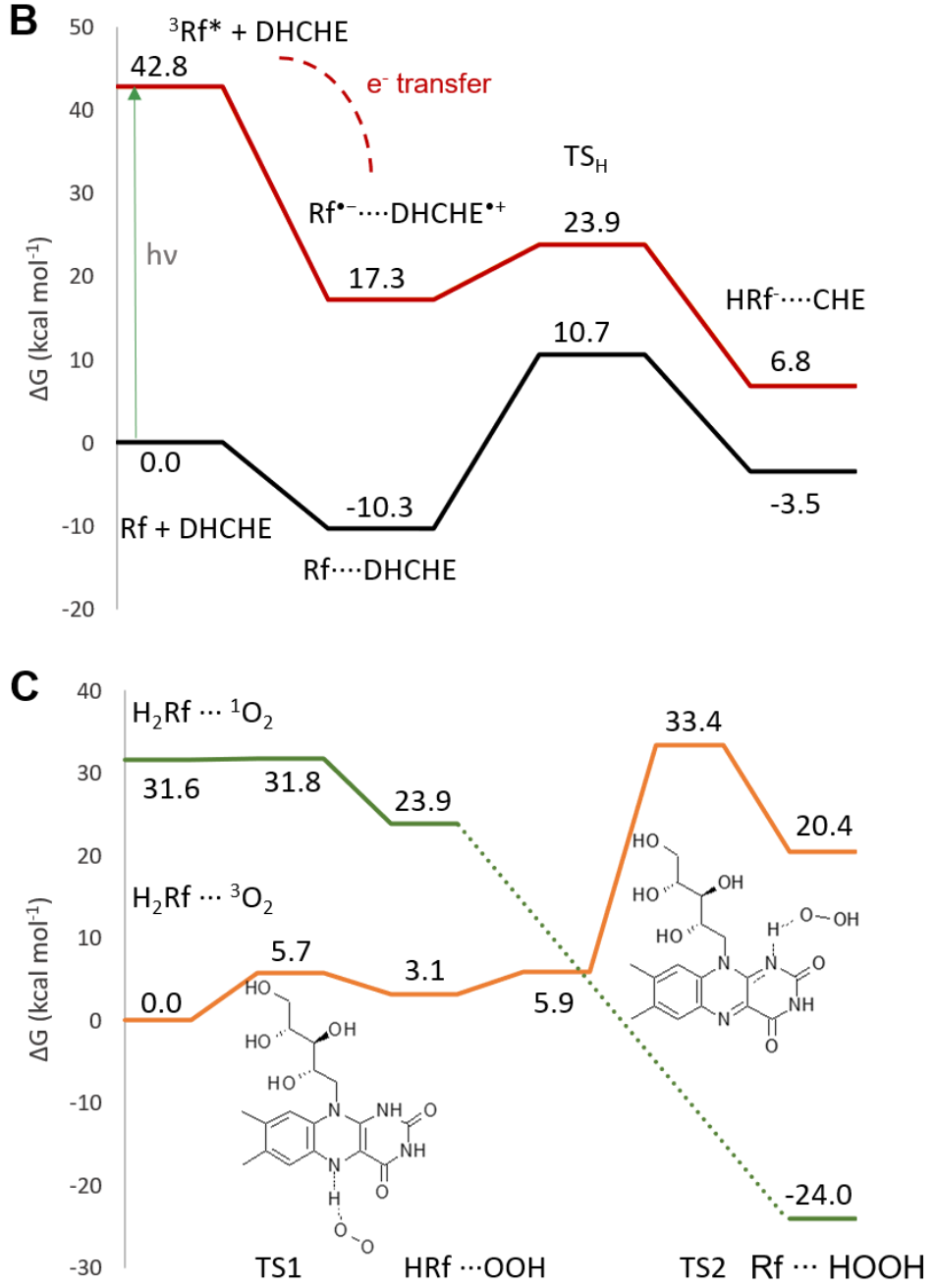

Figure 2. Outcomes of computational exploration: A) photophysical behaviour of Rf, including excitation energies $(\mathrm{eV})$ of the potentially involved states, SOC $\left(\mathrm{cm}^{-1}\right)$ between them and HOMO and LUMO plots; B) free energy profile for Rf + DHCHE reaction leading to CHE production along the excited triplet (red line) and ground (black line) states of $\mathrm{Rf}$ (relative energies were calculated with respect to the sum of the energies of $\mathrm{Rf}$ in its ground state and DHCHE as reference; C) free energy profile for $\mathrm{H}_{2} \mathrm{Rf}$ conversion to $\mathrm{Rf}$ along triplet (orange line) and singlet (green line) surfaces, the relative energies were calculated considering the sum of $\mathrm{H}_{2} \mathrm{Rf}$ and ground state of oxygen $\left({ }^{3} \mathrm{O}_{2}\right)$ energies as reference. 

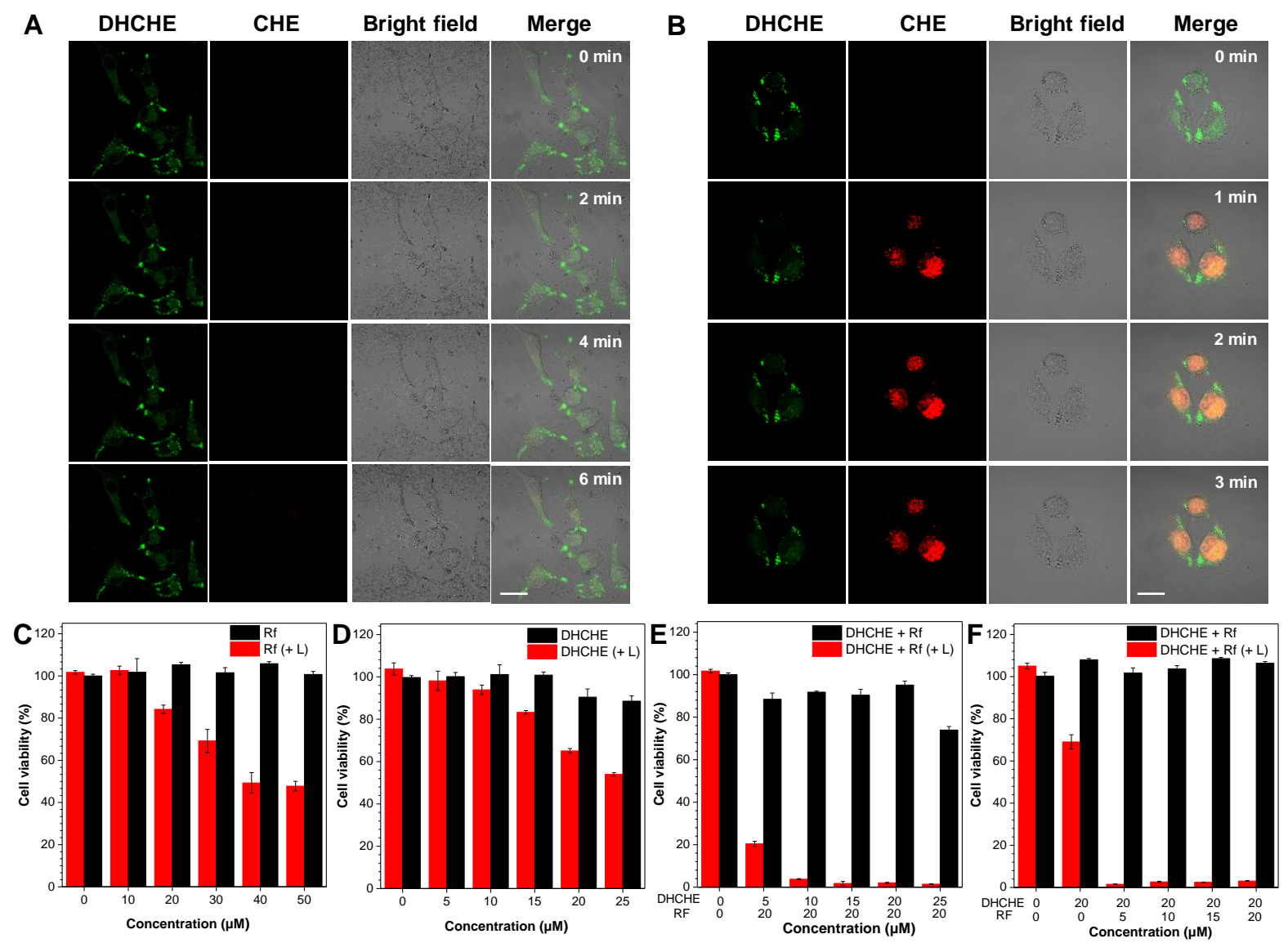

Figure 3. A B) Time-dependent CLSM images of A375 cells respectively incubated with DHCHE, "DHCHE + Rf" under white light irradiation $\left(34 \mathrm{~mW} \mathrm{~cm}^{-2}\right)$. [DHCHE] $=50 \mu \mathrm{M}$, $[\mathrm{Rf}]=10 \mu \mathrm{M}$. For DHCHE (green channel), $\lambda_{\mathrm{ex}}=405 \mathrm{~nm}, \lambda_{\mathrm{em}}=420-520 \mathrm{~nm}$. For CHE (red channel), $\lambda_{\mathrm{ex}}=488 \mathrm{~nm}, \lambda_{\mathrm{em}}=580-700 \mathrm{~nm}$. Scale bar $=20 \mu \mathrm{m}$. C-F) Cytotoxicity of A375 cells by treatment with Rf, DHCHE and "DHCHE + Rf" at different concentration under dark and white light irradiation $\left(34 \mathrm{~mW} \mathrm{~cm}^{-2}\right)$ for $10 \mathrm{~min}$. 

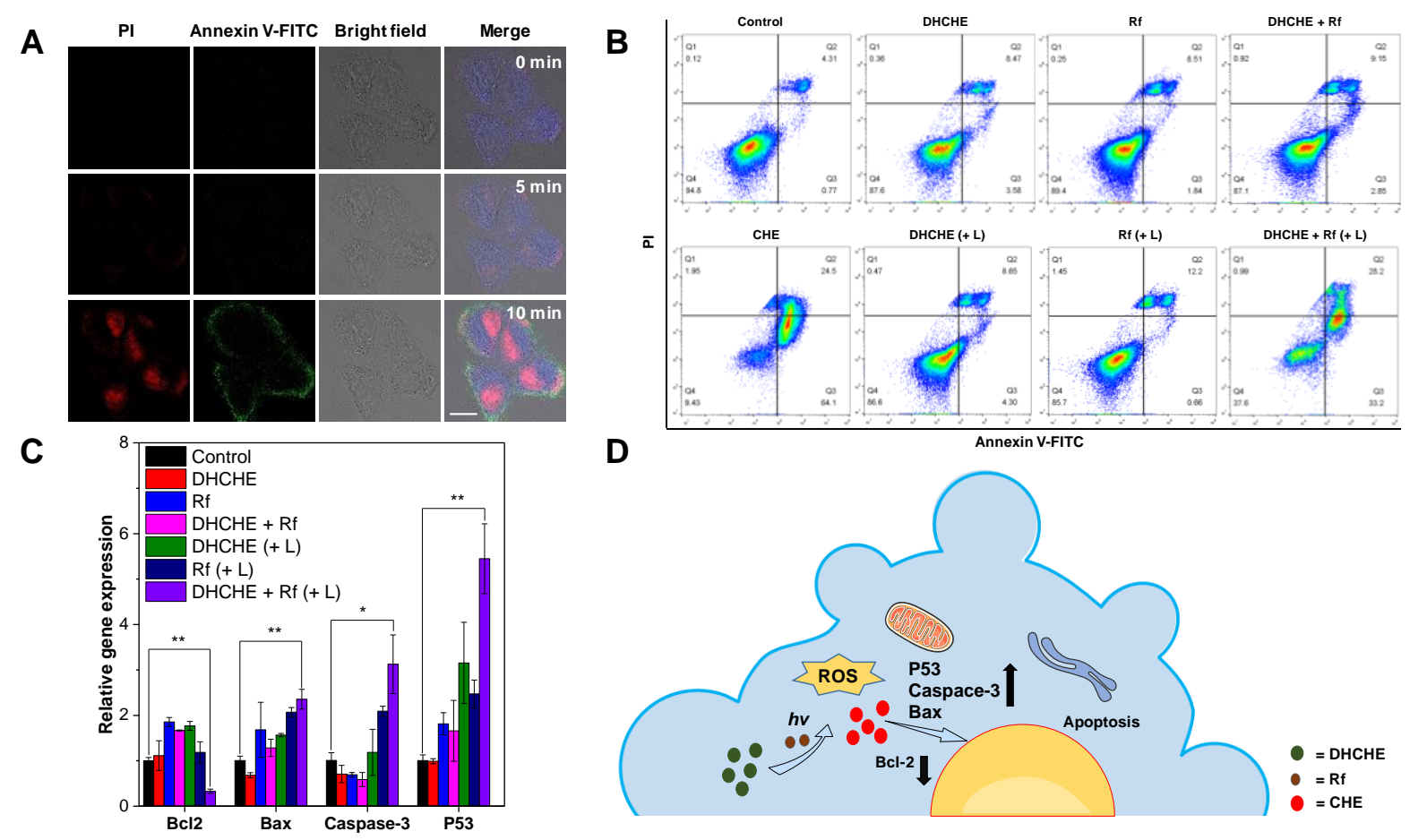

Figure 4. A) CLSM images of A375 cells treated with "DHCHE + Rf" and futher stained with Annexin V-FITC/PI. [DHCHE] $=50 \mu \mathrm{M}$, [Rf] $=10 \mu \mathrm{M}$. For Annexin V-FITC, $\lambda_{\mathrm{ex}}=488$ $\mathrm{nm}, \lambda_{\mathrm{em}}=510-550 \mathrm{~nm}$. For PI, $\lambda_{\mathrm{ex}}=543 \mathrm{~nm}, \lambda_{\mathrm{em}}=560-625 \mathrm{~nm}$. Scale bar $=20 \mu \mathrm{m}$. B) Flow cytometric analysis of A375 cells treated with DHCHE, Rf, "DHCHE + Rf (+ L)" under dark or white light irradiation $\left(34 \mathrm{~mW} \mathrm{~cm}^{-2}\right)$ for $10 \mathrm{~min}$. C) Gene expression levels of the proapoptotic (Bax, Caspase-3 and P53) and anti-apoptotic gene (Bcl2) analyzed by qRT-PCR. Expression levels were normalized to expression levels in control group cells. Bars with different characters are statistically different at $* \mathrm{p}<0.05, * * \mathrm{p}<0.01$ versus control. D) Schematic illustration of bioorthogonal photocatalyzed cancer chemotherapy strategy. 

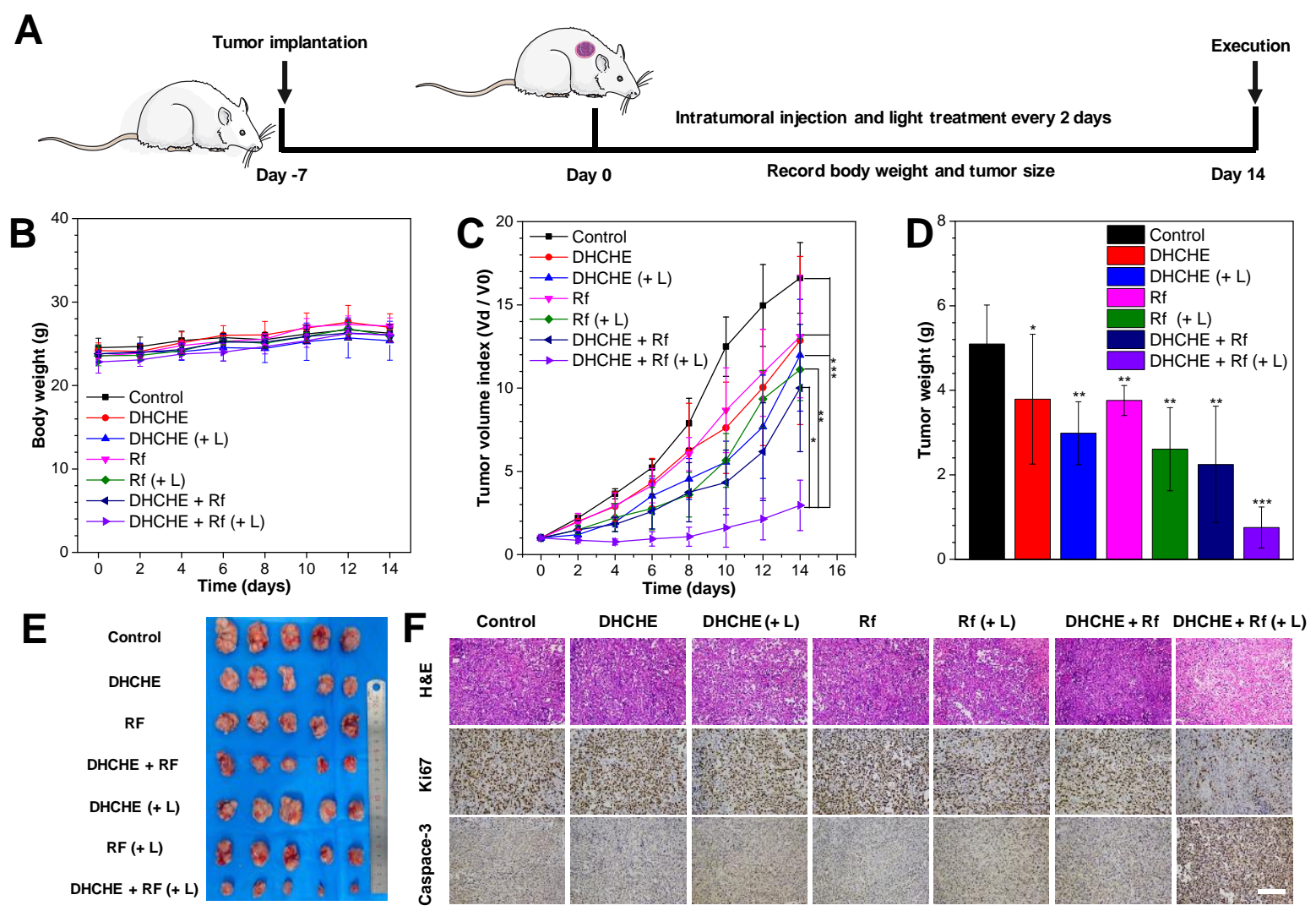

Figure 5. A) Schematic diagram of A375 tumor-bearing mice model development and treatment process. B) The body weight of tumor-bearing mice under control and treatment with DHCHE, DHCHE (+ L), Rf, Rf (+ L), "DHCHE + Rf", "DHCHE + Rf $(+\mathrm{L})$ ", respectively. C) the tumor volume index of tumor-bearing mice after different treatments for $14 \mathrm{~d}$. (Data are given as mean \pm standard deviation (SD), $\mathrm{n}=5$, ** $\mathrm{p}<0.01$, ***p $<0.001$ ). D) The average tumor weight of tumor-bearing mice under control and treatment with DHCHE, DHCHE (+ L), Rf, Rf (+ L), "DHCHE + Rf", "DHCHE + Rf $(+\mathrm{L})$ ", respectively. Bars with different characters are statistically different at $* p<0.05, * * p<0.01$, ***p $<0.001$ versus control. E) The photographs of tumors collected from different groups of A375 tumor-bearing mice at day 14. F) Representative images of H\&E, Ki67 and Caspace-3 staining from tumor sections after the indicated treatments. 


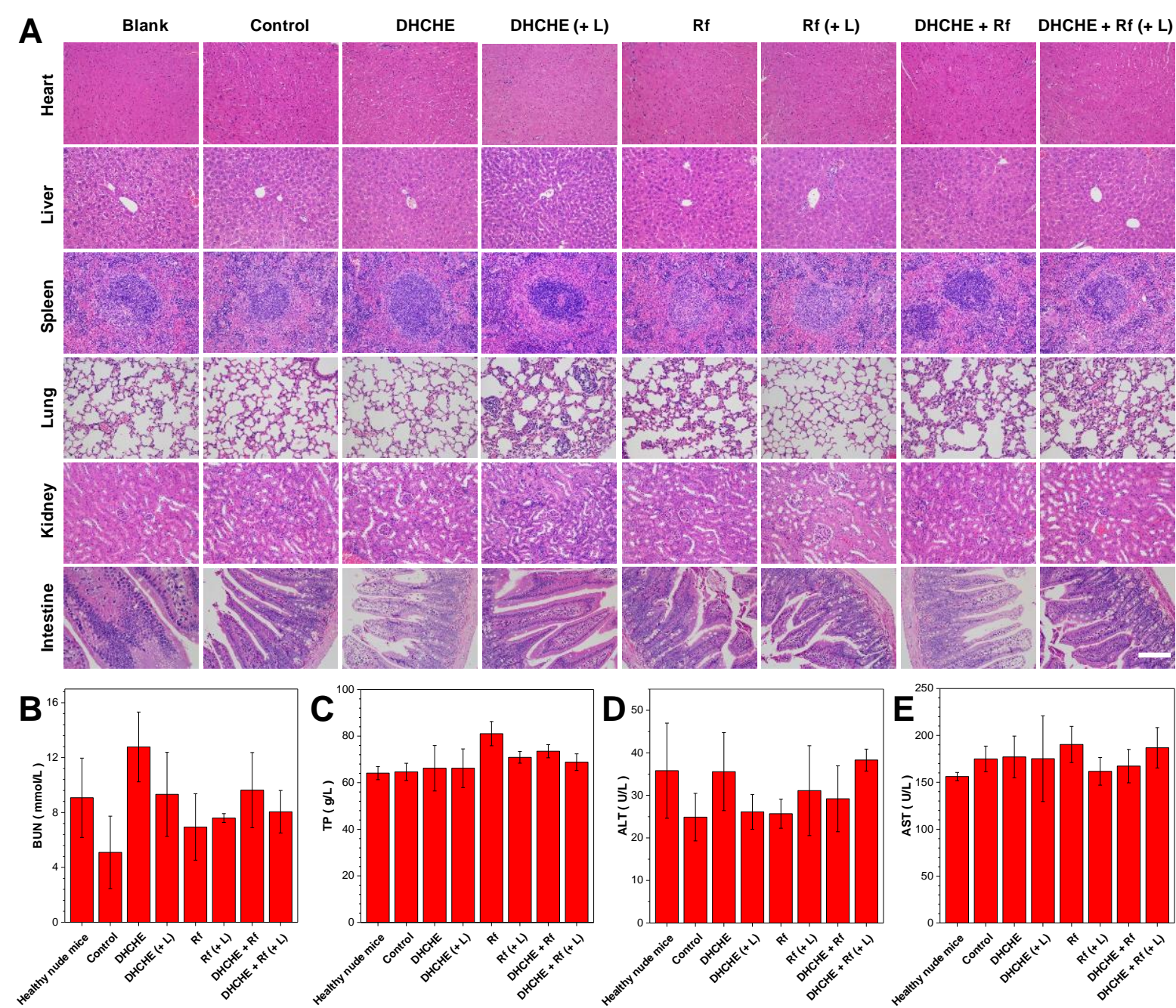

Figure 6. A) H\&E staining of the major organs sections from healthy mice and A375 bearing mice at day 14 under blank (healthy nude mice), control and treatment with DHCHE, DHCHE (+ L), Rf, Rf (+ L), "DHCHE + Rf", "DHCHE + Rf (+ L)", respectively. Scale bar $=100 \mu \mathrm{m}$. B-E) Blood biochemistry indices of BUN, TP, ALT, AST. (Data are given as mean \pm standard deviation $(\mathrm{SD}), \mathrm{n}=3$ ). 
TOC

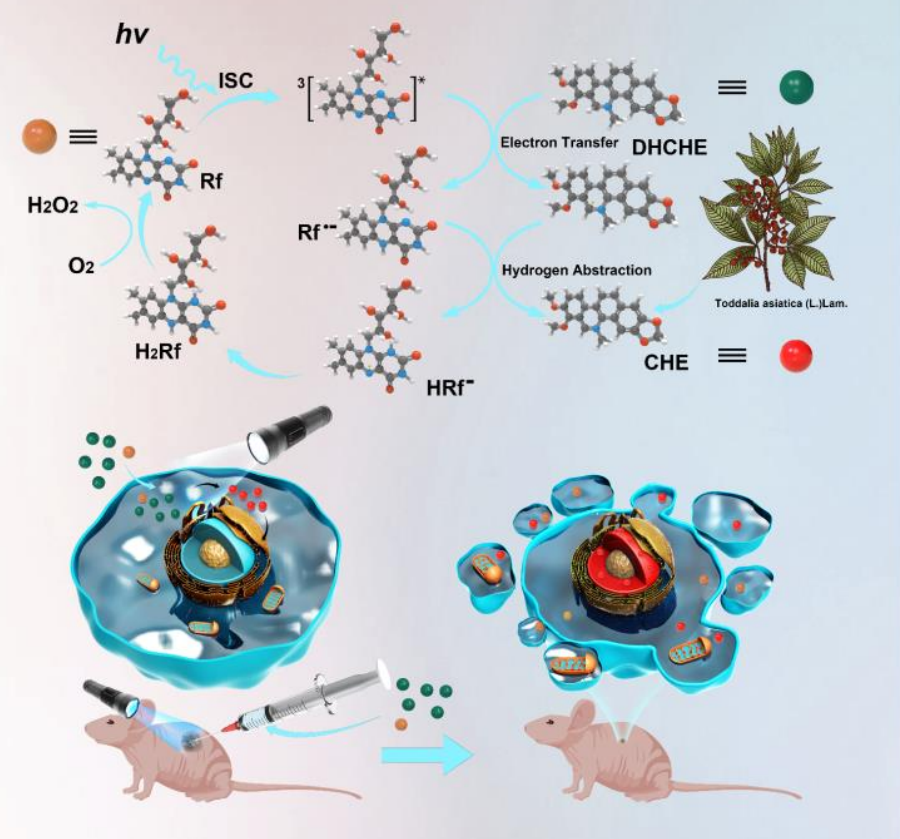




\section{Supporting Information}

\section{Bioorthogonal Photo-Catalytic Activation of an Anti-Cancer Prodrug by Riboflavin}

Xin Yang ${ }^{+}$, Limin $\mathrm{Ma}^{+}$, ${ }^{*}$ Hongwei Shao ${ }^{+}$Xia Ling, Mengyu Yao, Guowen Luo, Gloria Mazzone, * Meng Gao, * and Ben Zhong Tang*

X. Yang, X. Ling, Prof. M. Gao

National Engineering Research Center for Tissue Restoration and Reconstruction, Key Laboratory of Biomedical Engineering of Guangdong Province, Key Laboratory of Biomedical Materials and Engineering of the Ministry of Education, Innovation Center for Tissue Restoration and Reconstruction, South China University of Technology, Guangzhou 510006, China

E-mail: msmgao@scut.edu.cn

H. Shao, M. Yao, G. Luo, Prof. L. Ma

Department of Orthopedics, Guangdong Provincial People's Hospital, Guangdong Academy

of Medical Sciences, Guangzhou, Guangdong, 510080, China

E-mail: malimin7@126.com

Prof. Gloria Mazzone

Department of Chemistry and Chemical Technologies, Università della Calabria, 87036 Arcavacata di Rende, CS, Italy.

E-mail: gloria.mazzone@unical.it

Prof. B. Z. Tang

AIE institute, State Key Laboratory of Luminescent Materials and Devices, Center for Aggregation-Induced Emission, Guangdong Provincial Key Laboratory of Luminescence from Molecular Aggregates, Guangzhou International Campus, South China University of Technology, Guangzhou 510640; Shenzhen Institute of Aggregate Science and Technology, School of Science and Engineering, The Chinese University of Hong Kong, Shenzhen 518172, China

E-mail: tangbenz@cuhk.edu.cn

$\left.{ }^{+}\right]$These authors contributed equally to this work. 


\section{Experimental Section \\ Materials and chemicals}

DHCHE were prepared according to a literature method. ${ }^{[1]}$ Chelerythrine were purchased from Chengdu Herbpurify Co.,Ltd. Sodium borohydride $\left(\mathrm{NaBH}_{4}\right)$ and Riboflavin were purchased from Aladdin-Reagent Co.,Ltd. (China). $\mathrm{MeOH}$ and other solvents were purchased from Guangzhou Chemical Reagent Factory without further purification. Ultrapure water was supplied by Milli-Q Plus System (Millipore Corporation, United States). DCFH-DA was purchased from Sigma-Aldrich. Annexin V-FITC/PI Cell Apoptosis Kit was purchased from Becton, Dickinson and Company. Thiazolyl blue tetrazolium bromide (MTT) was purchased from BioFroxx Guangzhou Saiguo Biotech Co.,Ltd. Trolox was purchased from MacklinReagent Co. Ltd. (China). NADPH-Oxidase (NADPH-OX) ELISA Kit was purchased from Meimian Biotechnology (Yancheng, Jiangsu, China).

\section{Equipment and methods}

The UV-Vis absorption spectra were measured on a Shimadzu UV-2600 spectrophotometer, medium scanning rate, and quartz cuvettes of $1 \mathrm{~cm}$ path length. Photoluminescence spectra were recorded on a Hitachi F-7000 spectrofluorometer. Confocal lasing scanning microscopic (CLSM) images were obtained on the confocal microscope (Zeiss Laser Scanning Confocal Microscope, LSM880, Germany). The cell viability assay was conducted on a microplate reader (Tecan Infinite M200 PRO). Flow cytometry was measured on a BD FACScelesta system by counting 10000 gated cells. The concentration of serum NADPH-OX was measured using ELISA (the reagent kit was provided by Meimian Biotechnology (Yancheng, Jiangsu, China)).

\section{HPLC analysis}

HPLC was performed using Shimadzu LC-20A system (Shimadzu Corp., Kyoto, Japan) equipped with a SPD-M20A photodiode array (PDA) detector operating at $254 \mathrm{~nm}$. Separation was achieved using a WondaSil C18 column $(250 \times 4.6 \mathrm{~mm}, 5 \mu \mathrm{m})$ (Shimadzu 
Corp., Kyoto, Japan) working at $40{ }^{\circ} \mathrm{C}$. Mobile phase A was $0.2 \mathrm{v} / \mathrm{v} \%$ phosphoric acid in $\mathrm{H}_{2} \mathrm{O}$, and B was acetonitrile. A linear gradient of mobile phase B (0-10 min, increased from 20 to $100 \%$; $10-15 \min , 100 \%, 15-17 \mathrm{~min}$, decreased from 100 to $20 \%, 17-25 \mathrm{~min}, 20 \%$ ) with a

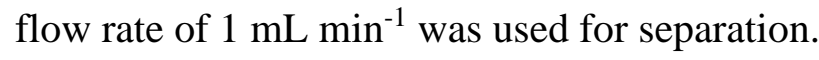

\section{Cyclic voltammetry measurement}

The cyclic voltammetry $(\mathrm{CV})$ measurements were performed on a $\mathrm{CH}$ Instruments $\mathrm{CHI} 760 \mathrm{E}$ electrochemical analyzer with a glass carbon disc as the working electrode, a platinum wire as the counter-electrode and $\mathrm{Ag} / \mathrm{Ag}^{+}$as the reference electrode. The redox couple ferrocenium / ferrocene was used as the internal standard at a rate of $50 \mathrm{mV} \mathrm{s}^{-1}$. Tetrabutylammonium hexafluoro-phosphate dissolved in anhydrous dimethyl formamide and $\mathrm{CH}_{2} \mathrm{Cl}_{2}(0.1 \mathrm{M})$ was respectively used as the electrolyte for the negative and positive scans.

\section{Cell culture}

A375 cells were purchased from ATCC and cultured in DMEM (Dulbecco's Modified Essential Medium) high-glucose with $1 \%$ penicillin-streptomycin, 10\% FBS (fetal bovine serum) at $37{ }^{\circ} \mathrm{C}$ in a humidified incubator with $5 \% \mathrm{CO}_{2}$ atmosphere. Dulbecco's Modified Essential Medium (DMEM) was purchased from Gibco (Life Technologies). Phosphate buffered saline (PBS), fetal bovine serum (FBS), penicillin and streptomycin were purchased from Thermo Fisher Scientific.

\section{Cytotoxicity experiment}

The cell viability was assessed by MTT assay. The A375 cells were seeded into 96-well plates $\left(1 \times 10^{4}\right.$ cells/well) for $24 \mathrm{~h}$. Subsequently, the cells were rinsed with PBS and further treated with various concentrations of Rf, DHCHE, CHE, "DHCHE + Rf", "CHE + Rf”. After incubation for $0.5 \mathrm{~h}$, for the light $(+\mathrm{L})$ groups, the cells were irradiated under white light irradiation $\left(34 \mathrm{~mW} \mathrm{~cm}^{-2}\right.$ ) for $10 \mathrm{~min}$. For dark groups, the A375 cells were kept under dark. Afterwards, the cells were further incubated for $24 \mathrm{~h}$, and rinsed with PBS for three time. Finally, after washing with PBS buffer for twice, freshly prepared MTT solution $\left(0.5 \mathrm{mg} \mathrm{mL} \mathrm{m}^{-1}\right.$, 
$100 \mu \mathrm{L}$ ) was added. After incubation at $37{ }^{\circ} \mathrm{C}$ for $4 \mathrm{~h}$, the MTT solution was removed and washed twice with PBS buffer. DMSO $(100 \mu \mathrm{L})$ was then added into each well and the plate was gently shaken for $10 \mathrm{~min}$ at room temperature to dissolve all the precipitates. The absorbance of sample and control wells at $570 \mathrm{~nm}$ was then measured by a microplate reader. Cell viability was then calculated by the ratio of the absorbance of sample wells to control cells.

\section{Quantitative Real-Time RT-PCR Analysis (qRT-PCR)}

A375 cells were seeded at $2.5 \times 10^{5} /$ well in 6 -well plates, and the culture medium was refreshed after cell attachment overnight. Cells were treated with DHCHE, CHE, Rf and "DHCHE + Rf" respectively under white light irradiation $\left(34 \mathrm{~mW} \mathrm{~cm}^{-2}\right)$ or dark for 10 min. Further culturing for $24 \mathrm{~h}$, the total RNA was extracted with the Total RNA Kit (Omega), RNA concentration was determined using Nanodrop spectrophotometer (Thermo Fisher Scientific, USA). Complementary DNA (cDNA) was synthesized based on total RNA with the first strand cDNA synthesis supermix Kit (Yeasen, China). Thereafter, cDNA was mixed with SYBR Green Supermix and primers. Quantitative reverse transcription PCR (qRT-PCR) was then performed on a Biorad CFX Connect Real-Time PCR Detection System ((BIO-RAD, USA). The expression of pro-apoptotic genes (Caspase3, Bax, P53) and anti-apoptosis gene (Bcl-2) were detected and the amount of target transcript was normalized to GAPDH respectively. The analysis of the expression ratios was performed in accordance with $2^{-\Delta \Delta C T}$ method. The primer sequences are listed in Table S1.

\section{Computational Details}

Gaussian 16 has been used to perform quantum mechanical calculations. ${ }^{[2]}$ All molecular geometry optimizations have been accomplished at the density functional theory (DFT) level by using the B3LYP hybrid exchange-correlation functional ${ }^{[3-4]}$ in implicit water $(\varepsilon=78.4)$ solvent with the Tomasi's implicit polarizable continuum model (PCM) ${ }^{[5-6]}$. Grimme dispersion corrections for non-bonding interactions have been included using atom pairwise 
additive scheme denoted as D3. ${ }^{[7]}$ The $6-311 \mathrm{G}^{* *}$ basis set has been used to describe all the atoms. The located stationary points have been checked by vibrational analysis at the same level of theory to confirm their nature of minima or transition states. The involved transition states have been carefully checked by intrinsic reaction coordinate (IRC) analysis. ${ }^{[8]}$ Enthalpies and Gibbs free energies have been calculated using standard statistical procedures at $298 \mathrm{~K}$ and $1 \mathrm{~atm}$ from total energies, including zero-point and thermal corrections. The optimized structures of $\mathrm{Rf}$ and DHCHE have been used to compute the vertical excitation energies at the TD-DFT level with the same protocol used for the optimization calculations. To ascertain the possibility of an intersystem spin crossing from a bright singlet state to a triplet one, spin-orbit matrix elements have been computed using the quadratic-response TDDFT approach, ${ }^{[9,10]}$ within the atomic-mean field approximation ${ }^{[11]}$ as implemented in the ORC Acode. ${ }^{[12,13]}$ 
Table S1. Primer sequences used in qRT-PCR.

\begin{tabular}{ccc}
\hline Gene & Forward primer sequence (5'-3') & Reverse primer sequence (5'-3') \\
\hline GAPDH (Human) & CAAGAGCACAAGAGGAAGAGAG & CTACATGGCAACTGTGAGGAG \\
Bcl2 & GGTGGGGTCATGTGTGTGG & CGGTTCAGGTACTCAGTCATCC \\
Caspase3 & GGCGGTTGTAGAAGAGTTTCG & TCACGGCCTGGGATTTCAAG \\
P53 & GAGGTTGGCTCTGACTGTACC & TCCGTCCCAGTAGATTACCAC \\
Bax & AAACTGGTGCTCAAGGCCC & AAAGTAGGAGAGGAGGCCGT \\
\hline
\end{tabular}




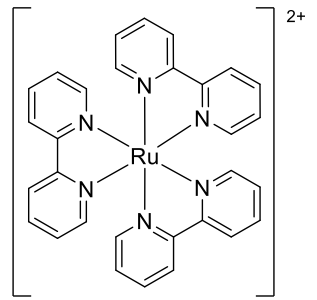

$\left[\mathrm{Ru}(\mathrm{bpy})_{3}\right]^{2+}$<smiles>CN(C)c1ccc2nc3ccc(=[N+](C)C)cc-3sc2c1</smiles>

Methylene Blue

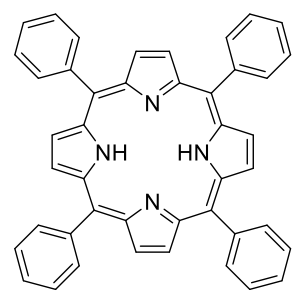

Tetraphenylporphyrin (TPP)

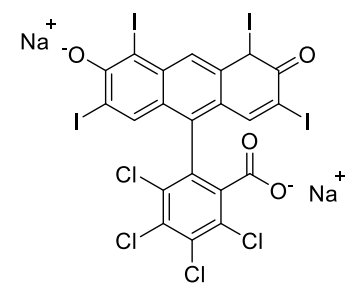

Rose Bengal 9-Mesityl-10-Methylacridinium Perchlorate

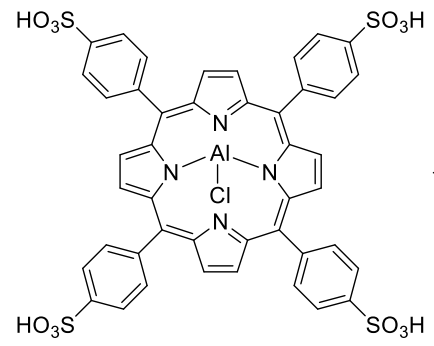

AIPcS-834
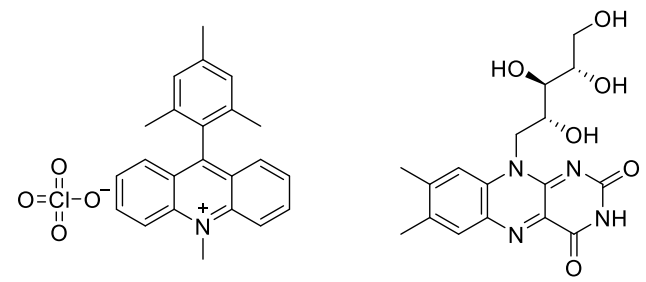

Figure S1. Chemical structures of screened photocatalysts. 

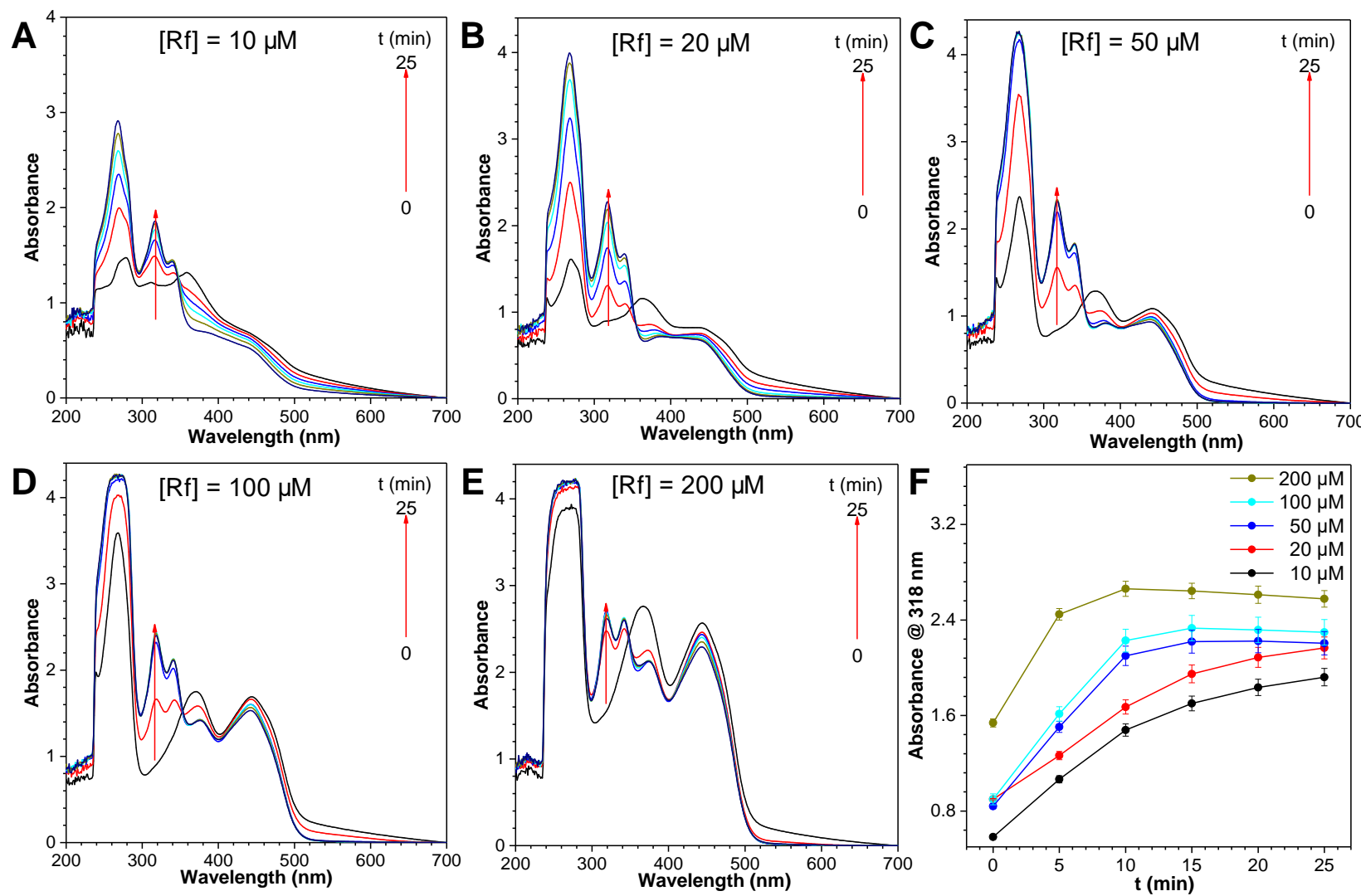

Figure S2. A-E) The UV-Vis absorption spectra and F) absorbance change at $318 \mathrm{~nm}$ of “DHCHE + Rf”(100 $\mu \mathrm{M}$ DHCHE and different concentration Rf) in Britton-Robinson buffer solution $(\mathrm{pH}=6, \mathrm{DMSO} /$ water $(\mathrm{v}: \mathrm{v}=10: 90))$ under white light irradiation $\left(34 \mathrm{~mW} \mathrm{~cm}^{-2}\right)$ for different time. $[\mathrm{DHCHE}]=100 \mu \mathrm{M}$. 


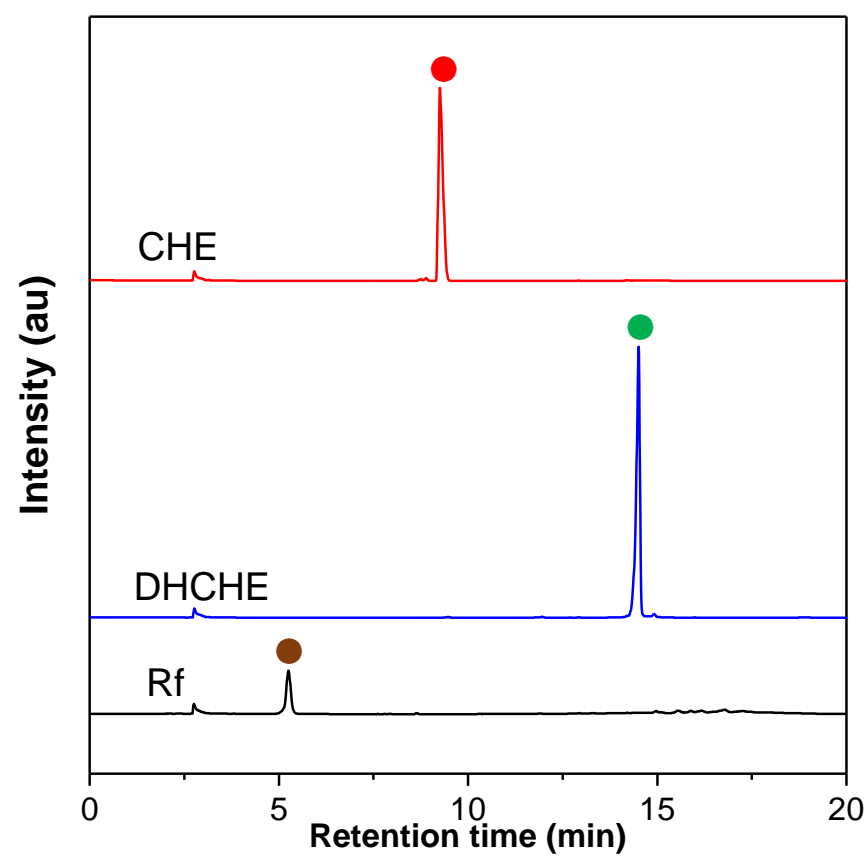

Figure S3. HPLC analysis DHCHE, CHE and RF under blue light irradiation $(500 \mathrm{~nm}, 50$ $\left.\mathrm{mW} \mathrm{cm}{ }^{-2}\right)$ at different time intervals. $\left([\mathrm{DHCHE}]=0.5 \mathrm{mg} \mathrm{mL}^{-1},[\mathrm{CHE}]=0.5 \mathrm{mg} \mathrm{mL}^{-1},[\mathrm{Rf}]=\right.$ $0.5 \mathrm{mg} \mathrm{mL} \mathrm{m}^{-1}$ ). Conditions: mobile-phase mixture of A: $0.2 \mathrm{v} / \mathrm{v} \%$ Phosphoric acid in $\mathrm{H}_{2} \mathrm{O}, \mathrm{B}$ : Acetonitrile. A linear gradient of mobile phase B (0-10 min, increased from 20 to $100 \%$, 10 $15 \mathrm{~min}, 100 \%, 15-17 \mathrm{~min}$, decreased from 100 to $20 \%, 17-25 \mathrm{~min}, 20 \%$ ) with a flow rate of 1 $\mathrm{mL} \min ^{-1}$ was used for separation. $\bullet \mathrm{CHE}, \bullet \mathrm{DHCHE}$ and $\bullet$ Rf. 

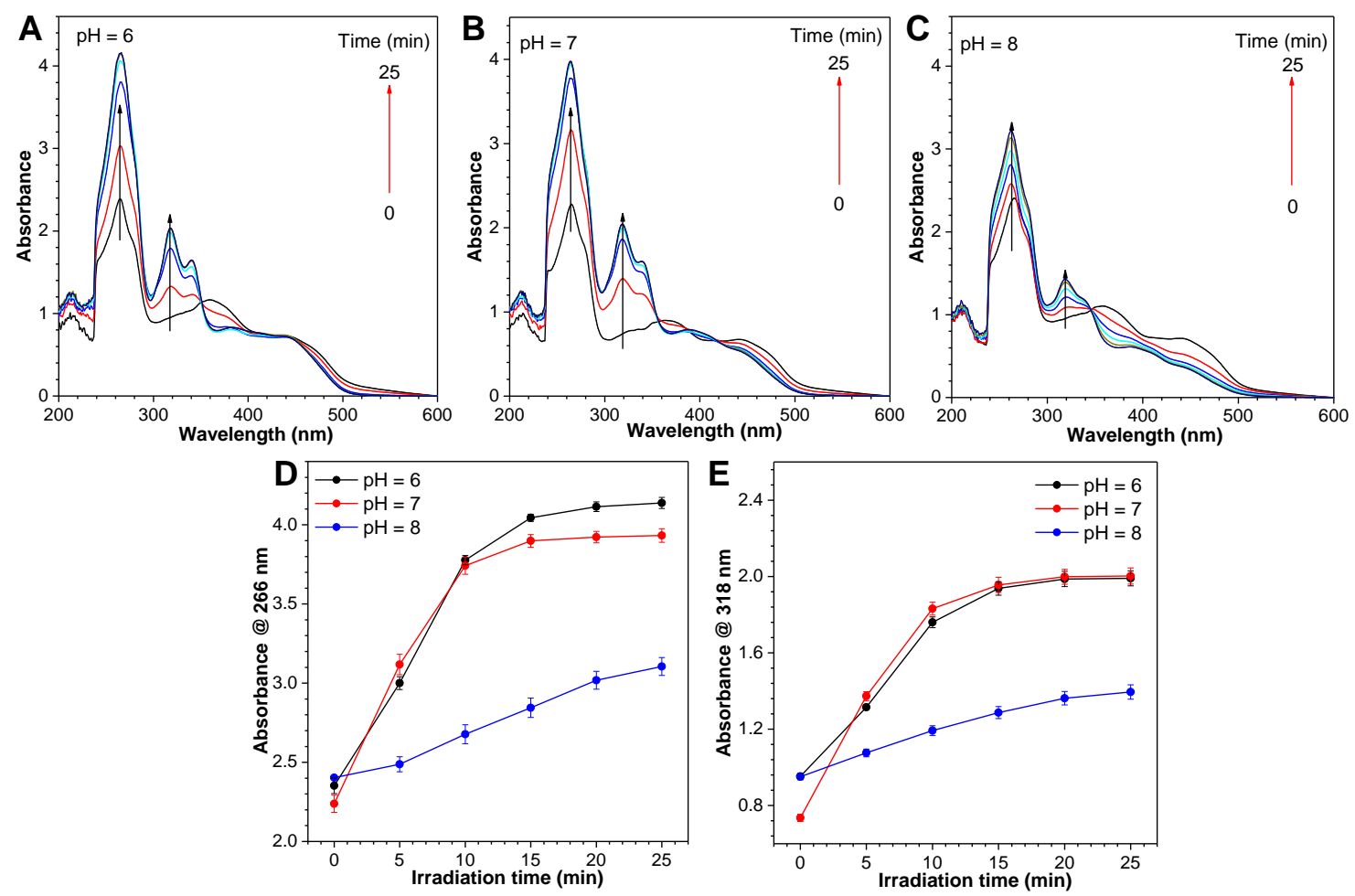

Figure S4. A-C) UV-vis absorption spectra and D E) absorbance change of "DHCHE + Rf" in Britton-Robinson buffer solution $(\mathrm{pH}=6,7,8, \mathrm{DMSO} /$ water $(\mathrm{v}: \mathrm{v}=10: 90))$ under white light irradiation $\left(34 \mathrm{~mW} \mathrm{~cm}^{-2}\right)$ for different time. [DHCHE] $=100 \mu \mathrm{M},[\mathrm{Rf}]=50 \mu \mathrm{M}$. 

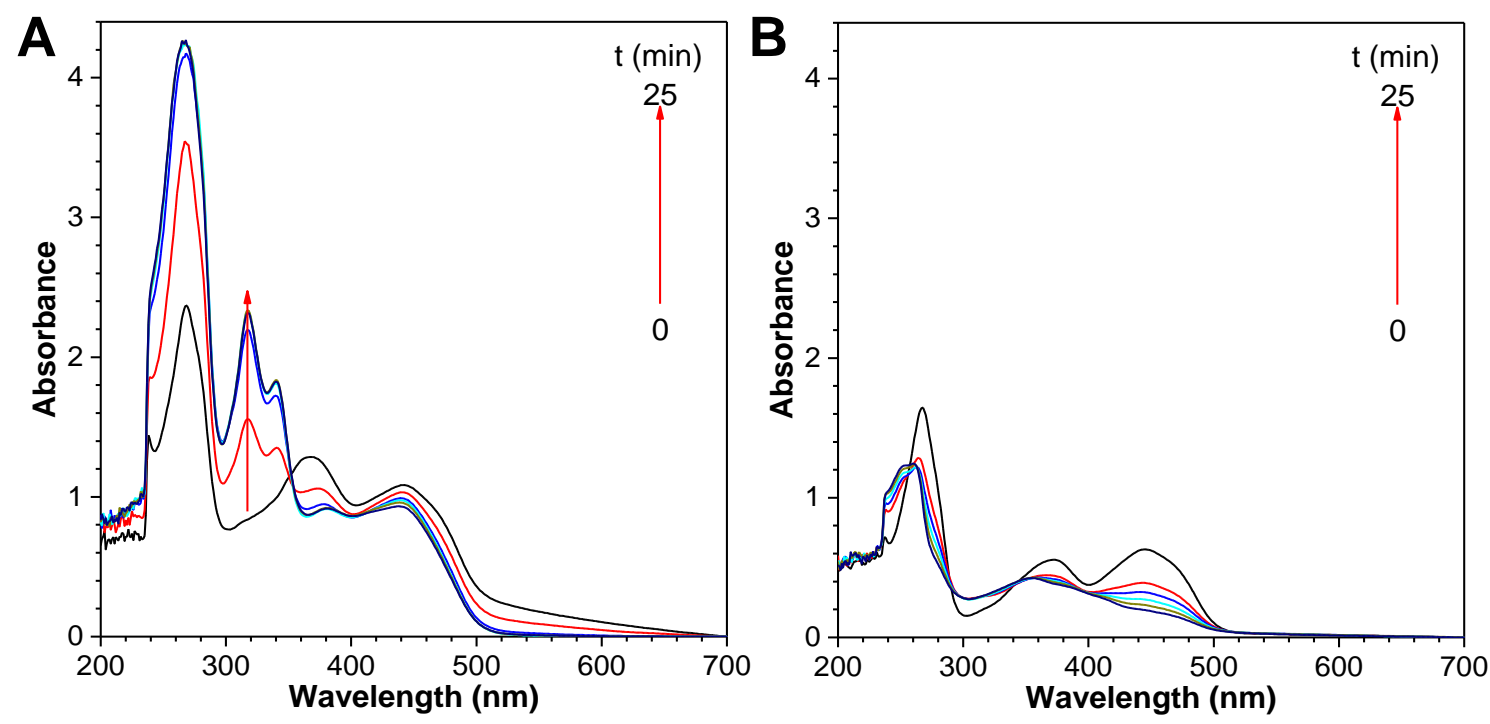

Figure S5. A B) The UV-Vis absorption spectra of "DHCHE + Rf" (100 $\mu \mathrm{M}$ DHCHE and 50 $\mu \mathrm{M}$ Rf) in Britton-Robinson buffer solution $(\mathrm{pH}=6, \mathrm{DMSO} /$ water $(\mathrm{v}: \mathrm{v}=10: 90))$ under white light irradiation $\left(34 \mathrm{~mW} \mathrm{~cm}^{-2}\right)$ for different time under (A) air and (B) argon. 

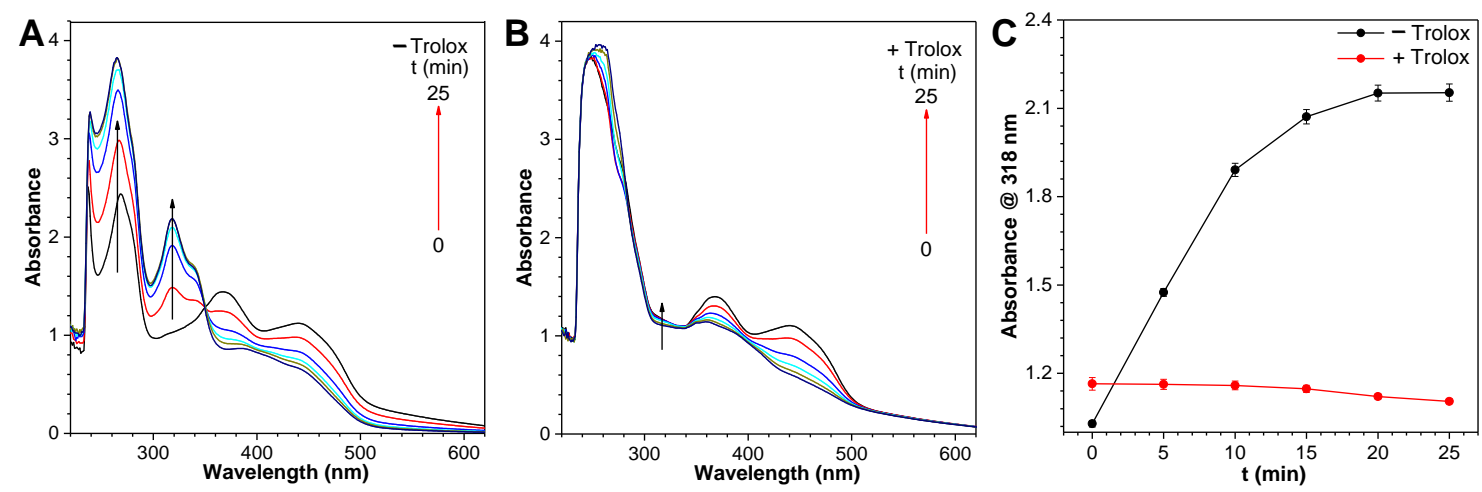

Figure S6. A B) The UV-Vis absorption spectra and C) absorbance at $318 \mathrm{~nm}$ of "DHCHE + Rf' in Britton-Robinson buffer solution $(\mathrm{pH}=6, \mathrm{DMSO} /$ water $(\mathrm{v}: \mathrm{v}=10: 90))$ in the A) absence and B) presence of Trolox under white light irradiation $\left(34 \mathrm{~mW} \mathrm{~cm}^{-2}\right)$ for different time. $[\mathrm{DHCHE}]=100 \mu \mathrm{M},[\mathrm{Rf}]=50 \mu \mathrm{M},[$ Trolox $]=500 \mu \mathrm{M}$. 

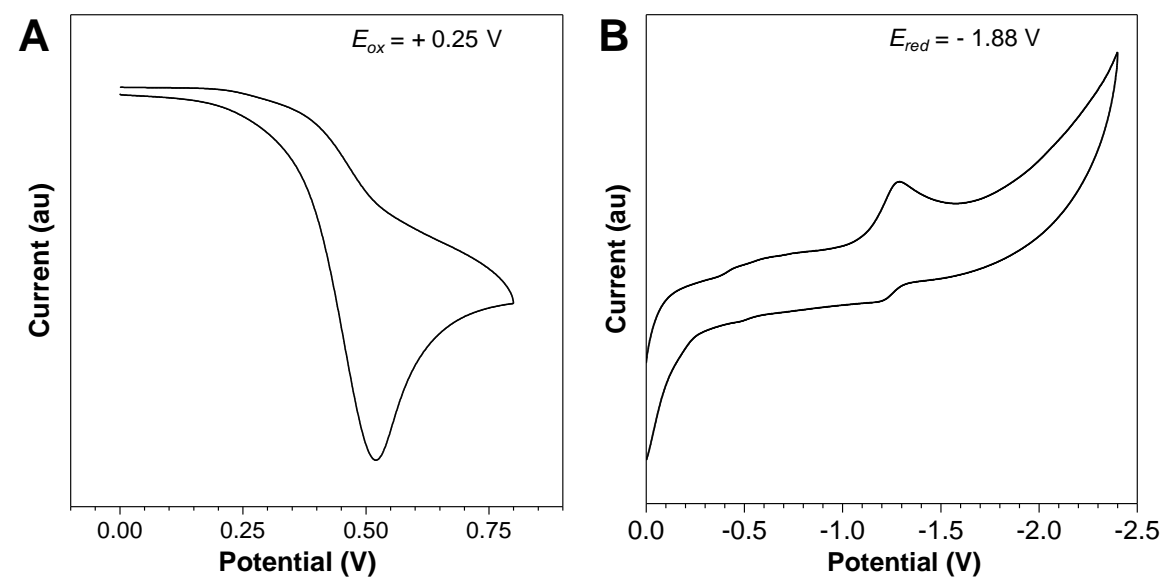

Figure S7 A) Oxidative and B) reductive cyclic voltammograms of DHCHE $\left(1.0 \mathrm{mg} \mathrm{mL}^{-1}\right)$ in $\mathrm{CH}_{2} \mathrm{Cl}_{2}$ and DMF containing $0.1 \mathrm{M} n-\mathrm{Bu}_{4} \mathrm{NPF}_{6}$, respectively. 
A
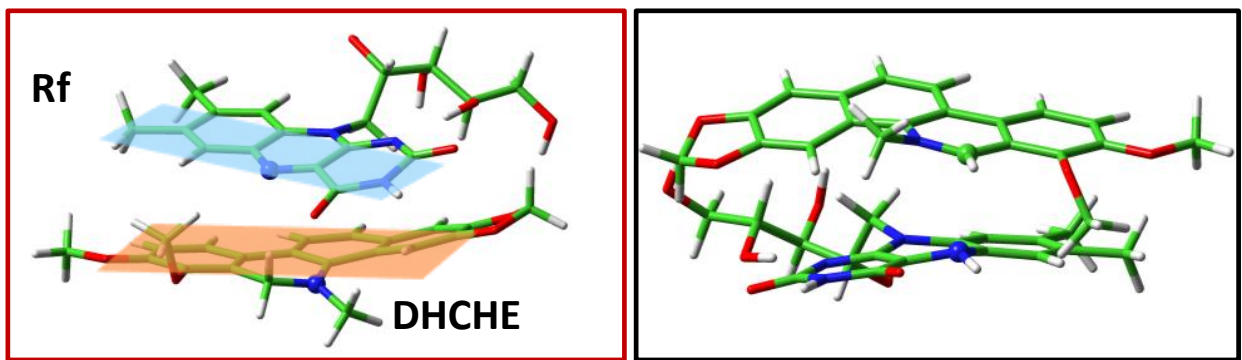

Rf....DHCHE

B

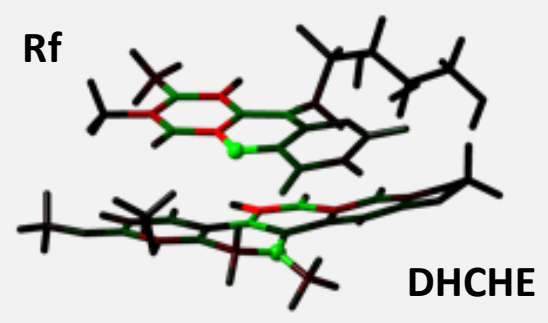

Color Range: -0.396 to 0.396

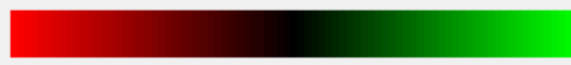

C
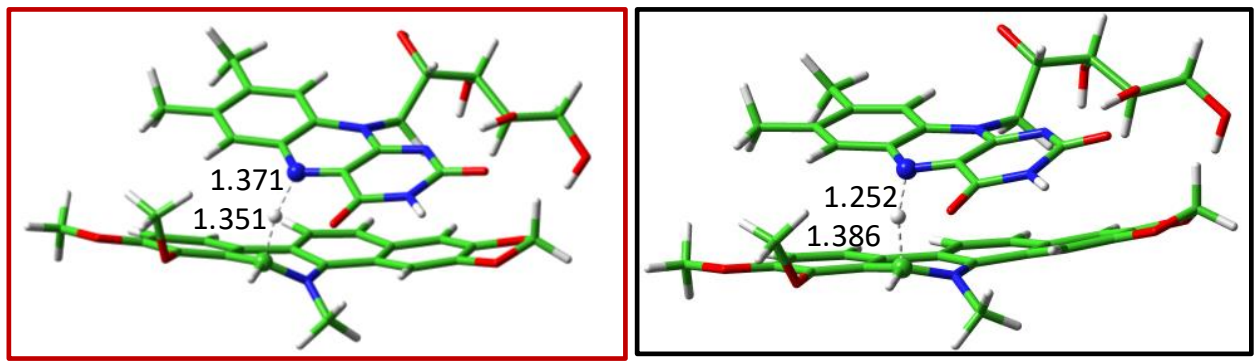

$\mathrm{TS}_{\mathrm{H}}$

Figure S8 A) Optimized structure of Rf $\cdots$...DHCHE adduct intercepted along triplet (red) and singlet (black) free energy surfaces, the $\pi-\pi$ stacking interaction is also highlighted; B) Mulliken spin density on Rf $\cdots$ DHCHE adduct; C) Optimized structures of the transition state for $\mathrm{H}$ abstraction, $\mathbf{T} \mathbf{S}_{\mathbf{H}}$, along triplet (red) and singlet (black) free energy surfaces. 


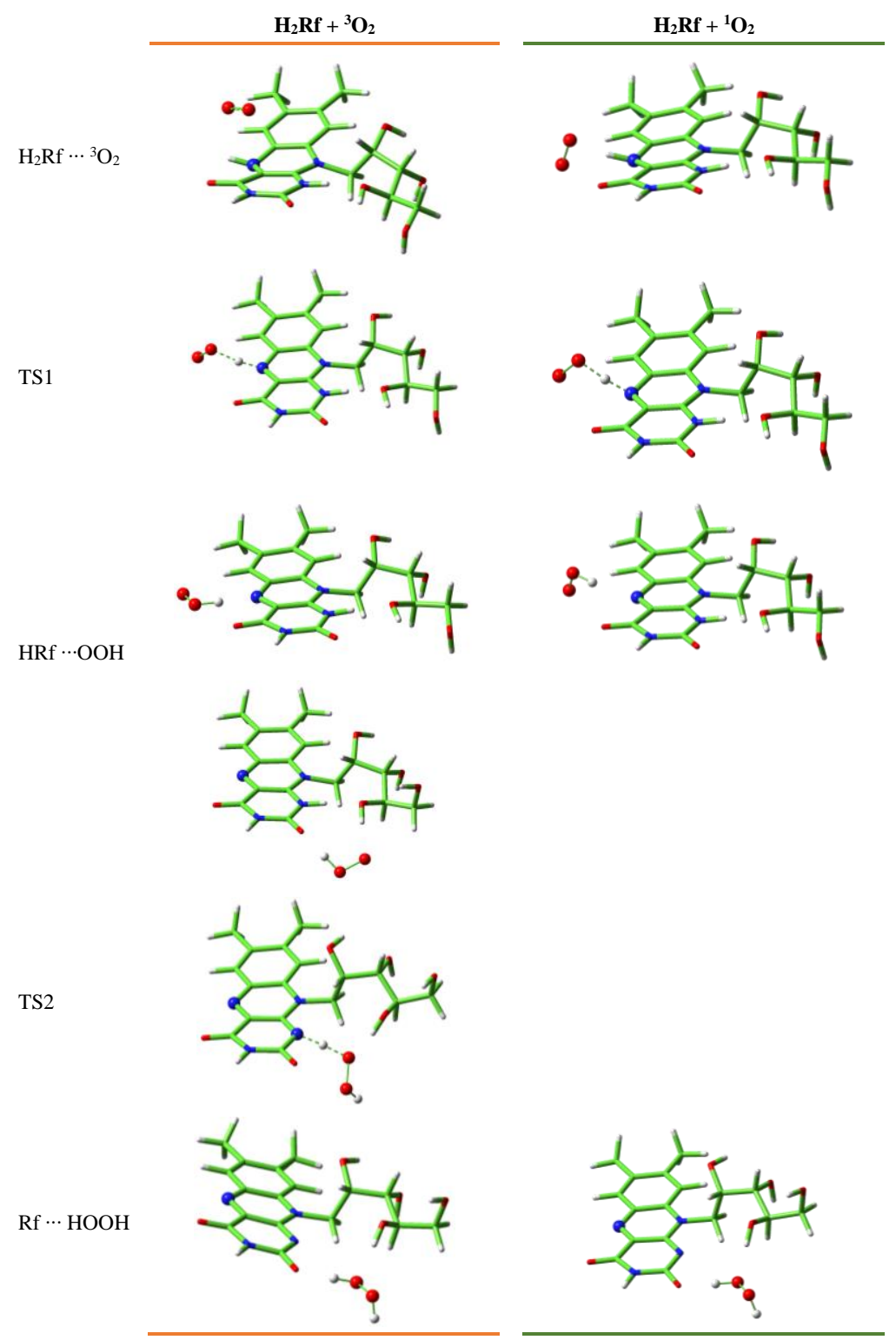

Figure S9 Optimized structures of stationary points intercepted along singlet and triplet free energy surfaces for $\mathrm{Rf}$ restoring by $\mathrm{O}_{2}$. 

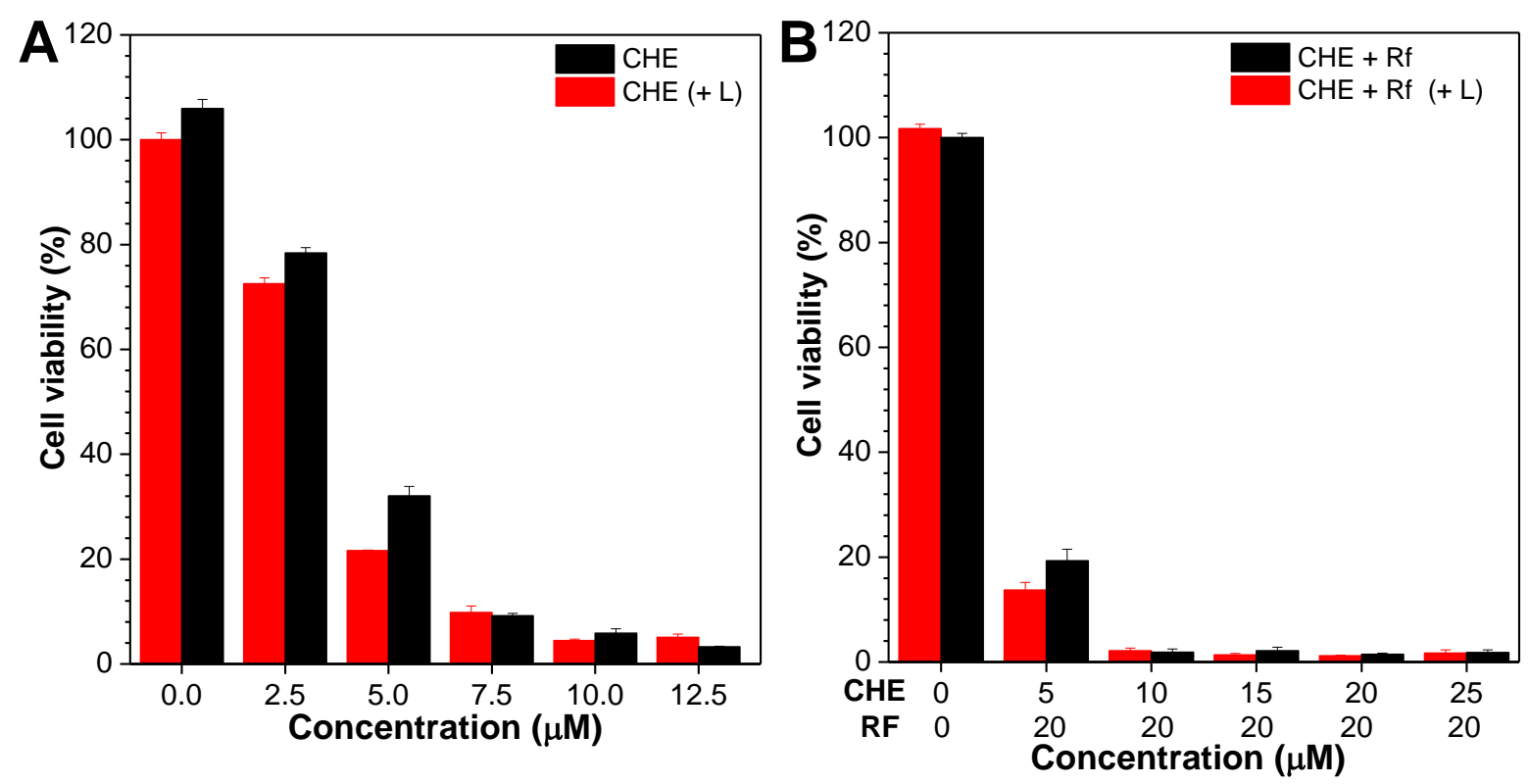

Figure S10 A B) In vitro cytotoxicity of A375 treated with CHE, “CHE + Rf” under dark and white light irradiation $\left(34 \mathrm{~mW} \mathrm{~cm}^{-2}\right)$ for $10 \mathrm{~min}$. 

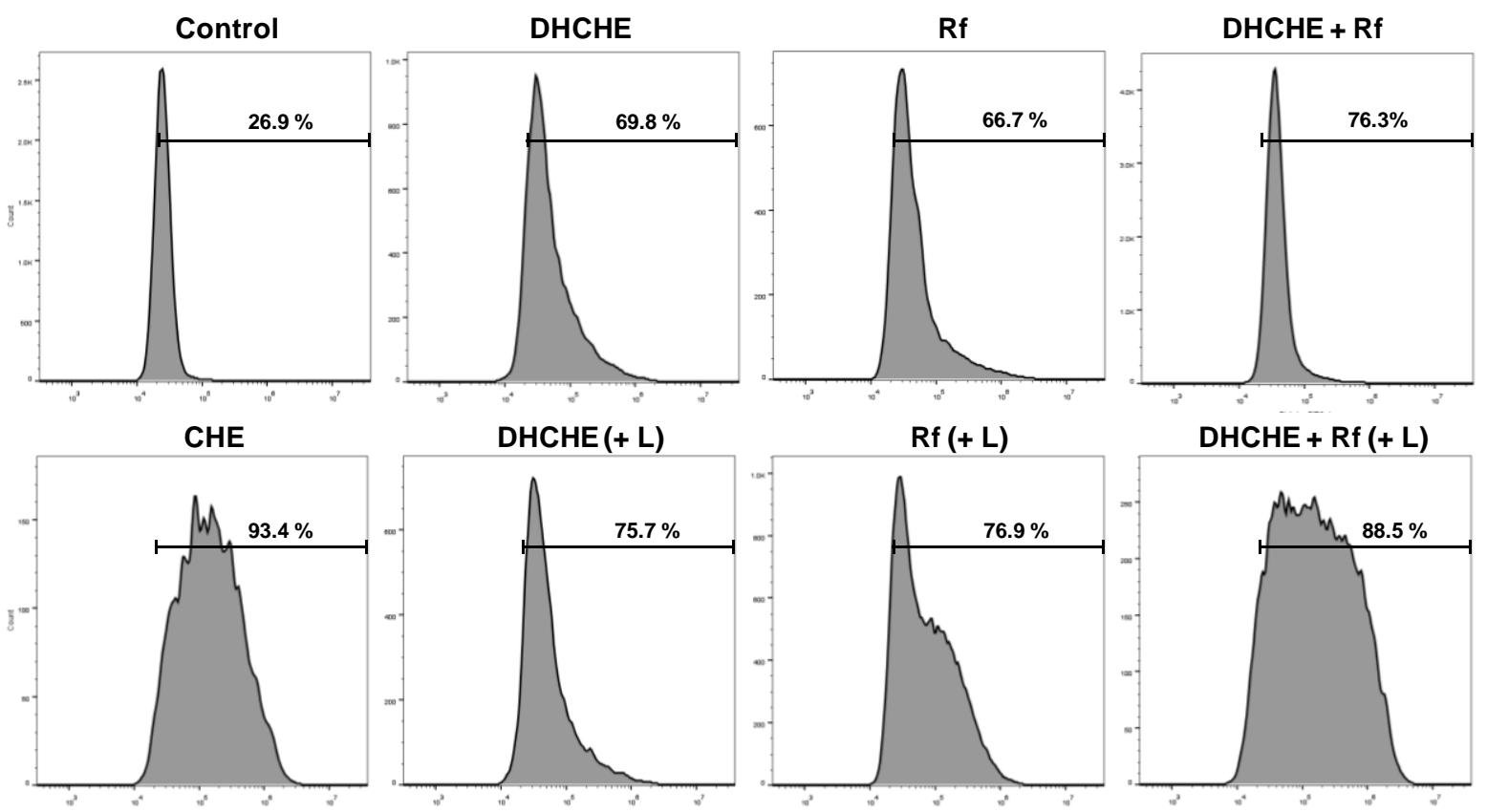

Figure S11. Flow cytometric analysis of intracellular ROS detection by DCFH-DA in A375 cells through respectively incubation with RF $(10 \mu \mathrm{M})$, DHCHE $(20 \mu \mathrm{M})$, CHE $(20 \mu \mathrm{M})$, and "DHCHE + Rf" (20 $\mu \mathrm{M}$ DHCHE and $10 \mu \mathrm{M}$ Rf) for $4 \mathrm{~h}$ under dark and white light irradiation $\left(34 \mathrm{~mW} \mathrm{~cm}^{-2}\right.$ ) for $10 \mathrm{~min}$. 


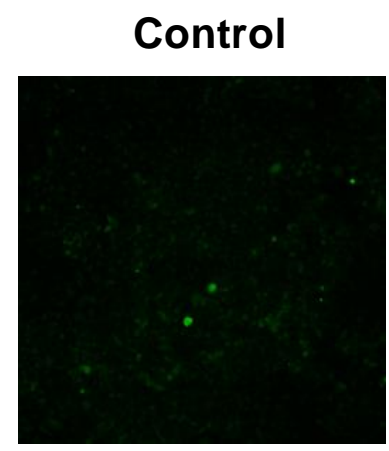

\section{CHE}

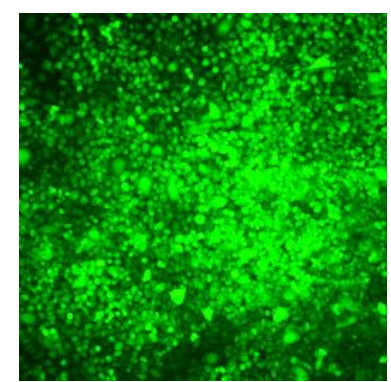

DHCHE

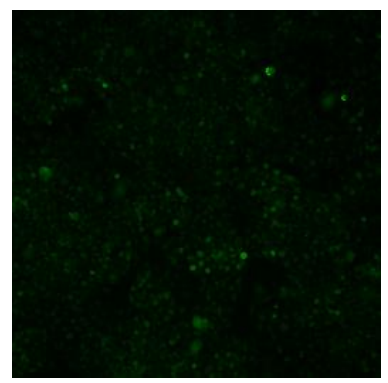

$\operatorname{DHCHE}(+\mathrm{L})$
Rf

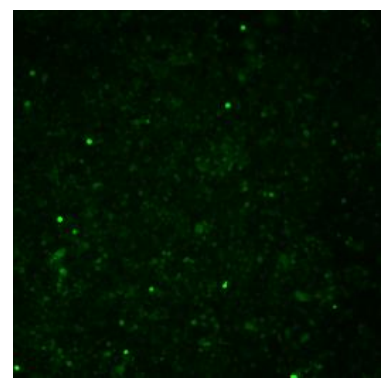

$\operatorname{Rf}(+L)$

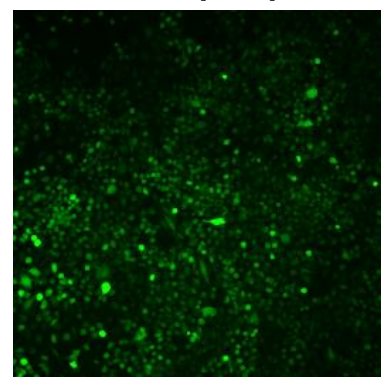

$\mathrm{DHCHE}+\mathbf{R f}$

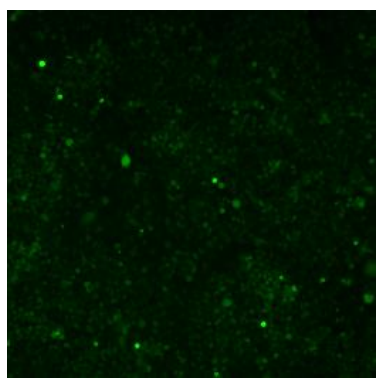

DHCHE + Rf (+ L)
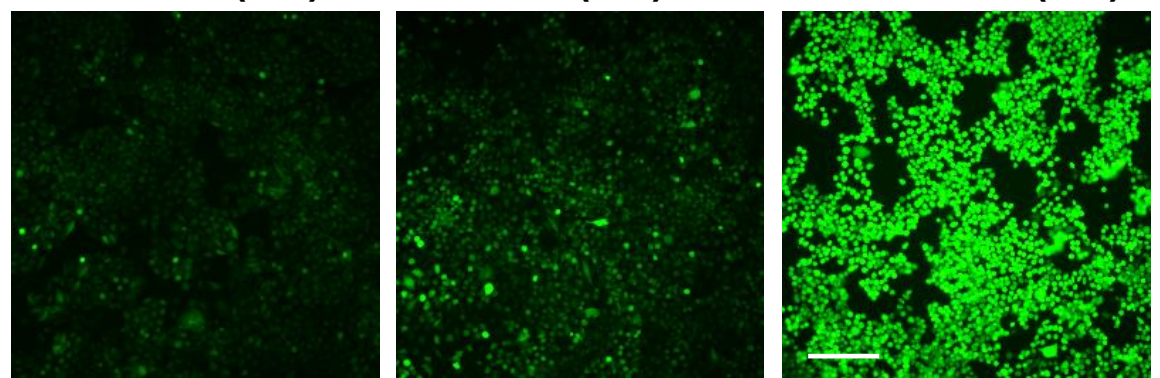

Figure S12. Fluorescence images of intracellular ROS detection by DCFH-DA in A375 cells through respectively incubation with $\mathrm{Rf}(10 \mu \mathrm{M})$, DHCHE $(20 \mu \mathrm{M})$, CHE $(20 \mu \mathrm{M})$, and “DHCHE + Rf” (20 $\mu \mathrm{M}$ DHCHE and $10 \mu \mathrm{M}$ Rf) under dark and white light irradiation (34 $\mathrm{mW} \mathrm{cm}{ }^{-2}$ ) for $10 \mathrm{~min} . \lambda_{\mathrm{ex}}=488 \mathrm{~nm}, \lambda_{\mathrm{em}}=510-540 \mathrm{~nm}$. Scale bar $=100 \mu \mathrm{m}$. 


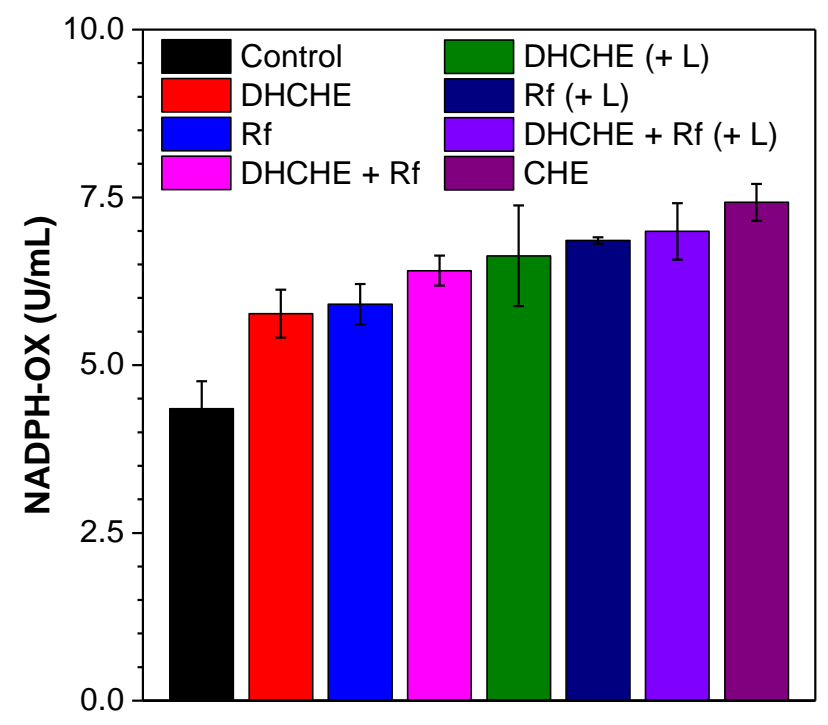

Figure S13. The NADPH-OX activity of A375 cells through respectively incubation with Rf (10 $\mu \mathrm{M})$, DHCHE $(20 \mu \mathrm{M})$, CHE $(20 \mu \mathrm{M})$, and "DHCHE + Rf" $(20 \mu \mathrm{M}$ DHCHE and $10 \mu \mathrm{M}$ Rf) for $4 \mathrm{~h}$ under dark and white light irradiation $\left(34 \mathrm{~mW} \mathrm{~cm}^{-2}\right)$ for $10 \mathrm{~min}$.

\section{References}

[1] S. Kumar, P. Deepak, S. Kumar, P. K. Gautam, A. Acharya, J. Canc. Res. Ther. 2013, 9, 693-700.

[2] M. J. Frisch, G. W. Trucks, H. B. Schlegel, G. E. Scuseria, M. A. Robb, J. R. Cheeseman, G. Scalmani, V. Barone, G. A. Petersson, H. Nakatsuji, X. Li, M. Caricato, a. V. Marenich, J. Bloino, B. G. Janesko, R. Gomperts, B. Mennucci, H. P. Hratchian, J. V. Ortiz, A. F. Izmaylov, J. L. Sonnenberg, D. Williams-Young, F. Ding, F. Lipparini, F. Egidi, J. Goings, B. Peng, A. Petrone, T. Henderson, D. Ranasinghe, V. G. Zakrzewski, J. Gao, N. Rega, G. Zheng, W. Liang, M. Hada, M. Ehara, K. Toyota, R. Fukuda, J. Hasegawa, M. Ishida, T. Nakajima, Y. Honda, O. Kitao, H. Nakai, T. Vreven, K. Throssell, J. A. Montgomery Jr., J. E. Peralta, F. Ogliaro, M. J. Bearpark, J. J. Heyd, E. N. Brothers, K. N. Kudin, V. N. Staroverov, T. A. Keith, R. Kobayashi, J. Normand, K. Raghavachari, A. P. Rendell, J. C. Burant, S. S. Iyengar, J. Tomasi, M. Cossi, J. M. Millam, M. Klene, C. Adamo, R. Cammi, J. W. Ochterski, R. L. Martin, 
K. Morokuma, O. Farkas, J. B. Foresman, D. J. Fox, 2016, Gaussian 16, Revision C.01, Gaussian, Inc., Wallin.

[3] A. D. Becke, J. Chem. Phys. 1993, 98, 5648-5652

[4] C. Lee, W. Yang, R. G. Parr, Phys. Rev. B 1988, 37, 785-789.

[5] S. Miertuš, J. Tomasi, Chem. Phys. 1982, 65, 239-245.

[6] S. Miertuš, E.Scrocco, J. Tomasi, Chem. Phys. 1981, 55, 117-129.

[7] S. Grimme, J. Antony, S. Ehrlich, H. Krieg, J. Chem. Phys. 2010, 132, 154104.

[8] K. Fukui, Acc. Chem. Res. 1981, 14, 363-368.

[9] Z. Rinkevicius, I. Tunell, P. Sałek, O. Vahtras, H. Ågren, J. Chem. Phys. 2003, 119, $34-46$.

[10] H. Ågren, O. Vahtras, B. Minaev, Adv. Quantum Chem. 1996, 27, 71-162.

[11] K. Ruud, B. Schimmelpfennig, H. Ågren, Chem. Phys. Lett. 1999, 310, 215-221.

[12] F. Neese, Wiley Interdiscip. Rev.: Comput. Mol. Sci. 2012, 2, 73-78.

[13] F. Neese, Wiley Interdiscip. Rev.: Comput. Mol. Sci. 2017, 8, e1327. 